\title{
Unmasking intraspecific variation in offspring responses to multiple environmental drivers
}

Spitzner, Franziska; Gimenez Noya, Jose; Meth, Rebecca; Harzsch, Steffen; Torres, Gabriela

\section{Marine Biology}

DOI:

$10.1007 / s 00227-019-3560-y$

Published: 01/08/2019

Peer reviewed version

Cyswllt i'r cyhoeddiad / Link to publication

Dyfyniad o'r fersiwn a gyhoeddwyd / Citation for published version (APA):

Spitzner, F., Gimenez Noya, J., Meth, R., Harzsch, S., \& Torres, G. (2019). Unmasking intraspecific variation in offspring responses to multiple environmental drivers. Marine Biology, 166(8), [112]. https://doi.org/10.1007/s00227-019-3560-y

\footnotetext{
Hawliau Cyffredinol / General rights

Copyright and moral rights for the publications made accessible in the public portal are retained by the authors and/or other copyright owners and it is a condition of accessing publications that users recognise and abide by the legal requirements associated with these rights.

- Users may download and print one copy of any publication from the public portal for the purpose of private study or research.

- You may not further distribute the material or use it for any profit-making activity or commercial gain

- You may freely distribute the URL identifying the publication in the public portal ?
}

Take down policy

If you believe that this document breaches copyright please contact us providing details, and we will remove access to the work immediately and investigate your claim. 
3 Unmasking intraspecific variation in offspring responses to multiple environmental drivers

${ }^{1}$ Universität Greifswald, Zoological Institute and Museum, Department of Cytology and 16 Evolutionary Biology, D-17498 Greifswald, Germany

$17{ }^{2}$ Biologische Anstalt Helgoland, Alfred Wegener Institute Helmholtz Centre for Polar and Marine 18 Research, D-24798 Helgoland, Germany.

$19{ }^{3}$ School of Ocean Sciences, College of Natural Sciences, Bangor University, LL59 5AB Menai 20 Bridge, UK.

$25 *$ Corresponding author:

26 Dr. Gabriela Torres, AWI, 27498 Helgoland, Germany.

$27+4947258193141$

28 gabriela.torres@awi.de 
Understanding organismal responses to environmental drivers is relevant to predict species capacities to respond to climate change. However, the scarce information available on intraspecific variation in the responses oversimplifies our view of the actual species capacities. We studied intraspecific variation in survival and larval development of a marine coastal invertebrate (shore crab Carcinus maenas) in response to two key environmental drivers (temperature and salinity) characterising coastal habitats. On average, survival of early larval stages (up to zoea IV) exhibited an antagonistic response by which negative effects of low salinity were mitigated at increased temperatures. Such response would be adaptive for species inhabiting coastal regions of freshwater influence under summer conditions and moderate warming. Average responses of developmental time were also antagonistic and may be categorised as a form of thermal mitigation of osmotic stress. The capacity for thermal mitigation of low salinity stress varied among larvae produced by different females. For survival in particular, deviations did not only consist of variations in the magnitude of the mitigation effect; instead, the range of responses varied from strong effects to no effects of salinity across the thermal range tested. Quantifying intraspecific variation of such capacity is a critical step in understanding responses to climate change: it points towards either an important potential for selection or a critical role of environmental change, operating in the parental environment and leading to stress responses in larvae.

Keywords: Carcinus maenas, global invaders, life cycles, marine larvae, multiple stressors. 
61 We are grateful to Julia Brinkmann, Stefan Eiler, Wladimir Escalante Alvarado, Michael Exton 62 and Simon Wolf for their assistance in animal husbandry. We thank the students of the "Schülerlabor" 63 (Alfred Wegener Institute, Helmholtz Centre for Polar and Marine Research, Helgoland, Germany) 64 for their help in collecting the berried females at the Helgoland intertidal. We acknowledge A. 65 Sombke for conceptual discussion and assistance during the initial phase of this project. 
Climate change is leading to a multiple modification of the physical and chemical properties of Earth habitats towards conditions that have not been experienced in the recent past (Gattuso and Hansson 2009; IPCC 2014; Gunderson et al. 2016; Boyd et al. 2018). Climate change affects multiple environmental variables that are key drivers of physiological and ecological processes (Brierley and Kingsford 2009; Hoegh-Guldberg and Bruno 2010; Doney et al. 2012; Sokolova et al. 2012, Torres et al. 2019). Whether such changes lead to positive or negative effects depends on species, communities or ecosystems, and hence they are difficult to predict. However, there is an urgent need to increase the capacity to predict how organisms will respond to such changes if we are to be able to mitigate the effects of climate change on ecosystem services and goods.

Biological responses to multiple environmental variables or drivers cannot be predicted from the isolated effects of each driver (also termed "stressors": Folt et al. 1999; Crain et al. 2008; Piggott et al. 2015; but we follow the logic of Boyd et al. 2018 in that the effects of a driver can be also positive). For instance, several reviews (Crain et al. 2008; Harvey et al. 2013; Kroeker et al. 2013; Côté et al. 2016; Gunderson et al. 2016) have found a widespread occurrence of synergistic or antagonistic responses at the level of individuals (e.g. survival, growth or development rates) to the community and ecosystem levels (e.g. species diversity, primary production). Synergistic and antagonistic responses are stronger or weaker, respectively, than those expected from the action of each single environmental driver (see e.g. Folt et al. 1999; Crain et al. 2008; Piggott et al. 2015 for definitions) and hence cannot be predicted from studies focusing on single drivers. Because such interactive effects are widespread and represent a major source of uncertainty, there is currently an important level of research effort focusing on understanding their nature. Characterising the nature of the responses is important for developing strategies to mitigate the effects of human activities on populations or ecosystems (Côté et al. 2016; Schäfer and Piggott 2018).

At the organismic level, an important source of uncertainty concerns intraspecific variation in the responses to multiple environmental variables, because most studies focus on inter- rather than intraspecific variations (but see e.g. Carter et al. 2013, Durrant et al. 2013). However, responses can vary within a species (and possibly within a population) due to parental effects (Marshall et al. 2008; Uller et al. 2013; Parker et al. 2017) and genetic variation (Nasrolahi et al. 2012; Durrant et al. 2013; Appelbaum et al. 2014), or perhaps due to both sources (Carter et al. 2013). Parental effects, i.e. the effects of the parental environment on offspring performance, are expected to occur in response to variations in maternal nutrition (Cowgill et al. 1984; Pond et al. 1996) or parental temperature (Donelson et al. 2011; Shama et al. 2014). Both sources of variation can affect, for instance, offspring 
100 size or body mass, which in turn can drive offspring performance (Giménez and Anger 2003; 101 Marshall et al. 2008).

102 Intraspecific variation can have important ecological consequences (Bolnick et al. 2011). Most 103 notably, if intraspecific variation in responses to environmental drivers is high, average trends do not 104 truly represent the magnitude of the species response to the drivers especially when such traits 105 contribute non-linearly to fitness, a phenomenon known as the Jensen inequality (Denny 2017). 106 Another important point is that an average lack of effect of an environmental driver can potentially 107 mask both positive and negative effects on the performance of individuals or lineages (Appelbaum et 108 al. 2014). Hence, studies addressing the magnitude of intraspecific variation in multiple driver 109 responses will potentially unmask the existence of phenotypes that thrive under environmental 110 change; they can unmask potential adaptive eco-evolutionary dynamics or portfolio effects (Bolnick 111 et al. 2011; Schindler et al. 2015) that will be relevant to species persistence. In that sense, low levels 112 of variation (due to genetic heterogeneity) would compromise population persistence and would 113 require specific conservation strategies targeting (at least) the offspring habitat. On the other hand, 114 variation that is non-adaptive, driven by a suboptimal maternal environment (e.g. see Parker et al. 115 2017), will indicate the need for conservation strategies targeting (at least) the maternal habitat. The 116 focus on intraspecific variation provides the stepping-stone towards understanding how trait variation 117 drives responses to climate change.

118 Here, we quantify intraspecific variation in multiple driver responses of larvae of the shore crab 119 Carcinus maenas to temperature and salinity. C. maenas, is native to Europe, but it is also considered 120 a global invader elsewhere (Roman and Palumbi 2004; Compton et al. 2010). C. maenas develop 121 through four zoeal stages and a megalopa settling on shore habitats (Spitzner et al. 2019); larvae occur 122 in coastal waters and semi enclosed seas, where they are exposed to variations in temperature and 123 salinity. Particularly marginal and semi-enclosed seas currently experience an important influence of 124 climate change (Philippart et al. 2011; Robins et al. 2015). We study a population located in the 125 German Bight (North Sea), that has been exposed to increases in temperature experienced over the 126 past decades (Wiltshire et al. 2010; Meyer et al. 2011), which in addition may undergo a further 127 increase of $1-3^{\circ} \mathrm{C}$ by 2100 (Schrum et al. 2016). We focus on salinity as a second driver because 128 regional changes in salinity are expected in response to climate change (Gunderson et al. 2016). Shore 129 crabs, as other coastal organisms, will necessarily have to deal with natural variations of salinity in 130 the new scenario of increased temperature, where increases in metabolic demands may not be 131 necessarily met by resources supply. From that perspective, climate change exposes coastal 132 organisms to conditions not previously experienced for many generations. We focus on larvae 133 because larval stages of marine invertebrates are often the most sensitive stage to multiple drivers 
134 (Przeslawski et al. 2015, Pandori and Sorte 2019) as their tolerance spectrum is often narrower 135 compared to their adults (Pechenik 1987; Charmantier 1998). Larvae determine gene flow and 136 population connectivity (Palumbi 2003; Cowen and Sponaugle 2009). Although there are studies 137 investigating the effect of temperature and salinity on C. maenas larvae (Dawirs 1985; Nagaraj 1993; 138 Anger et al. 1998), there is very limited information about the magnitude of intraspecific variation in 139 the response to these drivers.

140 We quantified the magnitude of intraspecific variation in the survival and duration of development 141 in larvae hatching from broods carried by ten different females collected over two years. As first step, 142 we report the average responses and then the variation from the average. For survival, we tested both 143 additive and multiplicative null models of responses. For duration of development, we tested additive 144 and multiplicative models, and evaluated responses with reference to predictions made by models 145 used in metabolic theories (O’Connor et al. 2007). By using such models, we expected to contribute 146 towards a mechanistic approach to study developmental responses of larvae to multiple 147 environmental drivers; such approach is needed for a better understanding of effects of climate change 148 on organisms, as much as for communities or ecosystems (De Laender 2018).

\section{Material and Methods}

\section{Animal husbandry, larval rearing and elemental analysis}

Carcinus maenas berried females were collected on the island of Helgoland (North Sea, German Bight, Latitude: 54.1771903, Longitude: 7.884409) on two consecutive years (May to August: 2016 and 2017). Larvae in the German Bight commonly experience temperatures of 15 and $18^{\circ} \mathrm{C}$ during spring and summer (Wiltshire et al. 2010). However, these temperatures are likely to increase in the future due to both steady increase in temperatures $\left(1-3^{\circ} \mathrm{C}\right.$ for end of century, Schrum et al. 2016) and increase in the frequency of warm years (Christidis et al. 2015). Salinities in the German Bight oscillate in the range of 20-33, depending on distance to the Elbe and Wesser Rivers (see e.g. Bils et al. 2012). Females whose embryos were at a late stage of embryonic development were transported to the laboratory (Helgoland, Germany). They were kept individually in 2-L aquaria filled with natural filtered $(0.2-\mu \mathrm{m})$ seawater at $18^{\circ} \mathrm{C}$ and fed with shrimps (Crangon crangon) which are the optimal conditions for ovigerous females of this species. Water was changed daily to ensure high water quality at hatching. To avoid confounding effects of acclimation to the laboratory conditions, only larvae that hatched within 48 hs. of collection of the female were used. 
factorial combination of four temperatures $\left(15,18,21\right.$ and $\left.24^{\circ} \mathrm{C}\right)$ and three salinities $(20,25$ and 32 = seawater) with the temperature $15^{\circ} \mathrm{C}$ and the natural seawater (salinity 32) as the control conditions. Temperatures below $20^{\circ} \mathrm{C}$ are considered within the range that may be experienced in nature while those above $20^{\circ} \mathrm{C}$ represent treatments of thermal stress; osmotic stress is expected with salinities of 25 and 20.

Temperatures were controlled by running experiments in temperature controlled rooms (range $\pm 0.5^{\circ} \mathrm{C}$ ); salinity (range \pm 0.1 salinity) was controlled using a salinometer (WTW). Experiments were run using natural seawater; waters of lower salinities were obtained by diluting natural seawater with appropriate amounts of tapwater. Daily, larvae were fed ad libitum with Artemia sp. and water was changed. During the daily water change, larvae were monitored for moults and dead larvae were recorded and discarded. We repeated the experiment five times each year, using five females per year. In both years, larval rearing was carried out by the same team, in order to minimise variation in larval responses due to different people manipulating larvae from different females.

We estimated body mass, carbon and nitrogen content in freshly hatched larvae in order to explore if body mass and nutritional reserves at the initiation of the larval phase would explain intraspecific variations in response to temperature and salinity. Previous studies (e.g. Giménez \& Anger 2003) have found positive correlations between reserves at hatching and survival and duration of development. Five replicate samples of larvae hatched of each female (50 freshly hatched Zoea I each) were used to determine elemental Carbon and Nitrogen (details in Torres et al. 2016). Larvae were quickly rinsed with distilled water, blotted dry with filter paper, placed in pre-weighted Aluminium cartridges and stored at $-20^{\circ} \mathrm{C}$ for subsequent analysis. To determine the dry mass (DW), all samples were freeze-dried for $48 \mathrm{~h}$. (Christ Alpha 1-4 freeze-drier) and then weighed on a microbalance (Sartorius SC2, nearest 0.0001-mg). Carbon and Nitrogen content were then determined using an elemental Analyser (vario MICRO cube CHNS analyser, Elementar Analysensysteme).

\section{Data analysis}

Cumulative survival until each zoeal stage was calculated as the percentage of survivors with reference to the initial number of freshly hatched larvae (i.e. at the start of the experiment). Cumulative duration of development until each stage was calculated as the time needed to reach the next developmental stage including developmental duration of previous stages. The combined effects of temperature and salinity, as well as intraspecific variations in the responses were evaluated through mixed modelling (Zuur et al. 2009; Galecki and Burzykowski 2013) by using the "Ime" function from 
the "nlme" package (Pinheiro et al. 2018) in R thought RStudio (RStudio Team 2018). The analyses were carried out in two steps: first, the random terms (i.e. the factor female with its interactions) were tested using restricted maximum likelihood (REML) fitting. Models with different random structure were compared through the Akaike information criteria (AIC). Models were ranked according to their AIC. The model with the lowest AIC score was selected for further analysis. When further analysis was not possible with the chosen model (with lowest AIC score), the second lowest AIC ranked model was used. In the second step, the fixed terms (all terms not containing the factor female) were estimated by maximum likelihood (ML). Tukey‘s HSD (Honestly Significant Difference) posthoc test was used to determine differences among treatment combinations. Tests for survival were performed after re-scaling the proportions using the equation $p^{\prime}=[p(50-1)+0.5] / 50$ in order to avoid inconsistencies with proportions $=0$.

211 We first evaluated the overall, larval responses using temperature and salinity as fixed factors, and 212 female of origin as random factors (crossed with the fixed factors). The full model contained estimates 213 of variance by combinations of female of origin, temperature and salinity but did not contain co214 variances between these terms; using the lme function, the random part of the model was coded as 215 "random $=$ list(ffem $=p d \operatorname{Diag}\left(\sim f s a l^{*}\right.$ ftemp $\left.)\right)$ ", where $f$ sal, ftemp and ffem denote salinity, temperature 216 and female of origin as factors. Alternative models contained random terms depending on the levels of fixed factors (e.g. as "random $=1+f$ sal|ffem" or "random $=1+$ ftemp $\mid$ ffem") or only random intercepts associated to the female of origin (e.g. as "random=1|ffem"). The best models corresponded to the full model, i.e. retaining random effects and indicating environmental dependent maternal influences on larval performance (see results).

For survival, we used logarithmic and logistic data transformations prior to the analysis. The logarithmic transformation was used in order to meet the requirements to test the independent (=multiplicative) effect of temperature and salinity on survival probabilities (i.e. an additive model in the logarithmic scale would correspond to a multiplicative model in the scale defined by survival probabilities), but its resulting residuals deviating considerably from the normal distribution (evaluated as qq-normal plots). The logistic transformation by contrast gave residuals with little deviations from the normal distribution. Overall, both approaches retained the same factors in the best models.

For duration of development we run analyses in the raw and log-transformed scales in order to determine whether effects were additive, multiplicative (=additive in the log-scale) or interactive in 231 both scales. In addition, we evaluated the thermal dependence of duration of development with reference to the so-called "universal temperature dependence" model (UTD: O'Connor et al. 2007, their equation 3 and Fig. 3). The thermal dependence of metabolism predicts an inverse relationship 
between temperature and developmental duration. Importantly, the UTD enables to test underpinnings of the combined responses to temperature and salinity as it is derived from a mechanistic model linking biochemical level processes and whole organisms metabolic rates. The UTD predicts that duration of development should follow a pattern described by the Arrhenius function, $A(T)=a \cdot e^{f}$ with $f=b /[k(T+273)]$, ( $\mathrm{T}$ is temperature in degrees Celsius; $a$ is a constant depending on the body mass, $b$ is the "activation energy" (measured in electron Volts, eV), and $\mathrm{k}=8.62 \times 10^{-5}$ is the Boltzmann constant). O'Connor et al. (2007) fitted the Arrhenius function, to duration of development of marine larvae of 69 species and found: $a=\exp (-22.47), b=0.64 \mathrm{eV}$. For the UTD, we log transformed the data of duration of development in order to use linear statistical models to determine if the thermal response followed the Arrhenius function. Under such transformation, we obtain $\log (D)=c_{0}+c_{1} \cdot f$. (with $c_{0}$ the intercept and $c_{1}$ the slope) as the null model; we refer to $f$ as the "Arrhenius transform" ( $f$ included $b=0.64$ ). If the logarithm of the duration of development were linear with respect to $f$, irrespective of salinity, then we retained the Arrhenius function as the best model explaining the thermal dependence of duration of development. In that case, effect of salinity should only appear in the intercept or the slope. Effects on only the intercept should manifest as parallel curves differing in the value of $c_{0}$; this would mean that the intercept, predicted to vary with body mass (term $a$ fitted by O'Connor et al. 2007), varies also with salinity. Effects on the slope $\left(c_{1}\right)$ would mean that the activation energy depends on the salinity. The alternative option is that the Arrhenius function does not predict effects of temperature on duration of development and in that case, the response should be non-linear. Here, we used a quadratic function as an alternative model: $\log (D)=c_{0}+c_{1} \cdot f+c_{2} \cdot f^{2}$. The linear and quadratic models were evaluated with polynomial regression, using the orthogonal polynomial approach for tests and the raw polynomial approach for the estimations of parameters. In both cases, models were run with two interacting covariates (salinity and $f$ ) and random terms defined by the combination of the factor duration of development was linear in $f$ at the control salinity $(=32)$, we introduced salinity in the models as a new covariate, $S t S=32-S$, i.e. standardizing each value of the salinity $(S)$ to that of the control. Hence, the fixed component of the full model was: $\log (D) \sim S t S+f+S t S: f+f^{2}+S t S: f^{2}$. If the Arrhenius function captures the functional response of development time, then such model would be reduced to: $\log (\mathrm{D}) \sim S t S+f+S t S: f$ or some simpler model containing $f($ e.g. $\log (\mathrm{D}) \sim S t S+f)$. If the response were not consistent in any salinity, the best model would be $\log (D) \sim S t S+f+S t S: f+$ $f^{2}$. If salinity drives the deviations from the Arrhenius function the best model would contain the quadratic term $S t S: f^{2}$. 
The role of initial larval nutritional reserves (body mass, Carbon and Nitrogen content) as predictor of survival and duration of development was evaluated through general least square models. First, survival and development data (four replicates per female) were averaged for each female and salinity-temperature combination; larval traits at hatching (three replicates per female) were also averaged and used as predictor variables. Separate analyses were run for dry mass, Carbon and Nitrogen per individual and percent of Carbon and Nitrogen. In each analysis, the full model contained, in the fixed structure the full factorial interaction ( $f$ sal:ftemp:trait) and the variance model included a correlation structure to control for repeated measures (corCompSymm constructor function) and variance heterogeneity (VarIdent constructor function). Model selection was carried out using the corrected Akaike information criterion (AICc) due to low number of replicates $(n=10$ for each treatment combination). Best models were represented using the package effects in R, which enables to construct scatterplots of partial effects of covariates and interaction terms.

\section{Results}

In order to describe intraspecific variation, we start with the quantification of the average responses and then compare variations among females with reference to the average responses.

\section{Average responses}

Best models evaluating cumulative survival rates included the interactive effect of temperature and salinity for all tested larval stages (Table 1). The average response consisted of an antagonistic effect whereby increased temperatures (especially at 21 , but also at $24^{\circ} \mathrm{C}$ ) mitigated the negative effects of low salinity on survival (Fig. 1a-c). One can appreciate the magnitude of the mitigating effect by comparing the observed survival under the combination of low salinity and high temperature with that expected under independent effects of these conditions. For example, the average survival up to the Zoea II at the control (temperature $=15^{\circ} \mathrm{C}$; salinity $=32$ ) was 0.74 and decreased to 0.34 at the same temperature but at the lowest salinity tested (Fig. 1a). At temperatures as high as 21 and $24^{\circ} \mathrm{C}$, survival at the lowest salinity $(20)$ were 0.56 and 0.50 ; these values were more than two times larger than the expected survival under the independent effects of temperature and salinity (expected for $21^{\circ} \mathrm{C}: 0.23=0.69 \times 0.34$; expected for $24^{\circ} \mathrm{C}: 0.24=0.70 \times 0.34$ ). At salinity 25 , survival was similar to that observed in seawater. The mitigation effect was strong in survival to stage II at both 21 and $24^{\circ} \mathrm{C}$, while it was only present at $21^{\circ} \mathrm{C}$ in survival to stages III (Fig. 1b) and IV (Fig. 1c).

Salinity and temperature affected the duration of zoeal development in opposite directions, with shortened development at high temperatures and lengthened development at low salinity (Fig. 1d-f). Best models for duration of development retained the salinity:temperature interaction term (Table 1). 
These interactive effects were antagonistic, especially in the raw scale (Fig. $1 \mathrm{~d}-\mathrm{f}$ ) whereby the effect of low salinity in increasing duration of development was mitigated at high temperatures. For example, at $15^{\circ} \mathrm{C}$, the effect of the lowest salinity (20) was to extend by 5.5 days the duration of development to Zoea II (with reference to the control salinity $=32$ ), while at $24^{\circ} \mathrm{C}$ it was extended only by two days (Fig. 1d). Similar responses were observed by comparing duration of development at salinity 25 vs. 32, i.e. clear effect of salinity at $15^{\circ} \mathrm{C}$ but rather similar values at $24^{\circ} \mathrm{C}$. An antagonistic response was found also for the duration of development to stages III (Fig. 1e) and IV (Fig. 1f), i.e. with stronger effects of low salinity at $15^{\circ} \mathrm{C}$ than at 21 or $24^{\circ} \mathrm{C}$. Duration of development at salinity 25 did not differ from that of larvae reared in seawater except in larvae reared at $15^{\circ} \mathrm{C}$. Interactive effects of temperature and salinity were also found in the logarithmic scale, but the effect was weaker; as compared to sea water, low salinity (20) extended development by 1.43-1.50 times at $15^{\circ} \mathrm{C}$ vs $1.20-1.34$ times at $21-24^{\circ} \mathrm{C}$. Overall, responses were not consistent either with an additive nor with a multiplicative model, although deviations from the latter were not large.

Duration of development to Zoea II and IV responded non-linearly to the Arrhenius function (Fig. 2; Table 2). In general, the strength of the non-linear relationship increased towards the lower salinities as captured by the quadratic term (Table 2). Overall, in agreement with the patterns observed in Figure 2, models predicted that reduced salinity would lead to a stronger deviation from the linear relationship between duration of development and the Arrhenius function.

\section{Intraspecific variability}

The analysis of interactive survival responses by female of origin revealed three main patterns (Fig. 3, top panels). First, in larvae from five females (females 1, 2, 5, 8 and 10) there were antagonistic patterns (in agreement with the general response), albeit of different magnitude (Fig. 3: compare salinity $20 \mathrm{vs}$. 32); for instance, the effect of low salinity on survival to Zoea II was much stronger at $15-18^{\circ} \mathrm{C}$ than at $21-24^{\circ} \mathrm{C}$ (see also Fig. S1 for subsequent stages). Second, in other two females ( 3 and 6), patterns differed qualitatively from the antagonistic response. In larvae produced by female 3 , there was no effect of salinity (two-way ANOVA $p>0.05$ for interaction term and salinity). In those produced by female 6, there was a multiplicative effect (two-way ANOVA, nonsignificant interaction but significant effect of salinity and temperature: both $p<0.001$ ) meaning that the cumulative effect of temperature and salinity was explained as the product of the effect of each factor in isolation. Third, there was an important overall variation in larval survival (e.g. compare females 8-9 vs. females 1-6) as well as variation in the temperature at which survival peaked in larvae 
reared at the lowest salinity (at $15-18^{\circ} \mathrm{C}$ in females $6-7$; at $21-24^{\circ} \mathrm{C}$ in females $1-5$ ). The patterns observed for survival to the second stage were also present for survival to stages III and IV (Fig. S2).

Interactive responses of duration of development were in general consistent with the average antagonistic pattern, whereby the effect of low salinity in extending development was mitigated at high temperatures (Fig. 3, bottom panels: exceptions: females 6 and 9: effects were additive). The predominance of antagonistic responses was also observed in the duration of development stages III and IV (Fig. S1). Such response was particularly strong in larvae produced by females 1 and 2 (Figs. 3 and S1) where, in addition, we observed the strongest deviation from the linear responses when development was plotted with respect to the Arrhenius transform (Fig. S3). Exceptions were found in larvae from females 6 and 9, where the pattern was synergistic (duration of development increased towards higher temperatures in larvae reared at the lowest test salinity). In larvae from these two females, the Arrhenius plot showed a rather linear response of development to temperature at low salinity (Fig. S2).

We used correlation analysis to explore relationships between larval performance at different temperature-salinity combinations; such correlations may reflect the nature of integration among traits that are relevant to stress tolerance (e.g. physiological compensatory mechanisms). Correlations of survival were positive, but variable (Fig. 4, Table S1). Correlations were high $(\mathrm{r}>0.7)$ and significant among treatments characterized by salinities 25 and 32 or at high temperatures but they decayed towards salinity 20 and low temperatures $\left(15\right.$ and $\left.18^{\circ} \mathrm{C}\right)$. Overall, larval survival at the control condition (temperature $=15^{\circ} \mathrm{C}$, salinity $=32$ ) was not a good predictor of survival under the highest temperature and the lowest salinity (Fig. 4, $r<0.62$, n.s. for all stages); hence, survival responses under the putative "multiple stressor" (temperature $=24^{\circ} \mathrm{C}$, salinity $=20$ ) treatment were not well predicted from those of the control. For duration of development, correlations were positive and high (Table S1); there was only a decay for specific treatment combinations. Duration of development under control conditions was a good predictor of that exhibited by larvae reared at the putative multiple stressor treatment for Zoea II and III ( $>0.75$, p<0.05), but not for Zoea IV (Table S1).

Relationships between survival and larval reserves at hatching were not significant for any indicator of larval nutritional reserves, stage or temperature-salinity combination. Relationships between duration of development and larval reserves at hatching were weak (Fig. S3 and S4), contingent on the salinity and present only for the $3^{\text {rd }}$ and $4^{\text {th }}$ zoeal stage only when percent Carbon (\%C) was used as descriptor of larval reserves. Best model for development to Zoea III retained $\% \mathrm{C}:$ salinity:temperature) and Zoea IV (\%C:salinity): in both cases, increases in percent Carbon led to a decrease in duration of development, in larvae reared at the lowest salinity treatment. 
Here we addressed the issue of intraspecific variation responses of larvae of the shore crab Carcinus maenas to key coastal environmental drivers (temperature and salinity). We first characterised the average responses and then examined deviations from the average; through such approach, we found an important level of intraspecific variation in the survival and duration of development. On average, we found an antagonistic response (both in survival and duration of development) that we call "thermal mitigation of low salinity stress", because negative effects of low salinity (lower survival or extended development) were mitigated by high temperature. The thermal mitigation of low salinity stress may be considered a form of cross-tolerance (Fregly 2011) consistent with that described for other coastal species (Kinne 1971; Anger 1991; Janas and Spicer 2008; González-Ortegón and Giménez 2014). Mechanistically, it might result from the fact that compensatory physiological mechanisms controlling osmoregulation are enhanced at high temperatures (Flügel 1963; Campbell and Jones 1989; Janas and Spicer 2008) through an increase in the capacity of mitochondria to produce ATP (Pörtner 2010). Extracellular osmoregulation for instance, is driven by pumping $\mathrm{Na}^{+}$by the $\mathrm{Na}^{+}-\mathrm{K}^{+}$-ATPase located in the ionocytes; intracellular regulation may also be more efficient at higher temperatures. Overall, antagonistic responses have important ecological relevance at the species to ecosystem levels (Côté et al. 2016; Lange and Marshall 2017). For example, the form of thermal mitigation studied here implies that a temperature increase may lead to temporary niche expansion, assuming that such increase does not change other critical environmental factors. Hence, under such scenario increased temperature may favour range expansion by improving larval performance in general (deRivera et al. 2007) and also providing zoeal stages with additional suitable habitats, characterised by moderately low salinity (but >20).

For duration of development the response was also antagonistic especially in the raw scale. Our best fit was a quadratic model based on the Arrhenius function, where the importance of the quadratic term increased because of responses at the combination of low salinities and temperatures. O'Connor et al. (2007) found that responses of duration of development to temperature, in larvae of a number of marine organisms, would fit better a quadratic model (albeit different in structure from ours), but they also found consistent fit of the UTD at temperatures $>7^{\circ} \mathrm{C}$. Explaining the non-linearity found by us might require the consideration of additional effects of low salinity, on e.g. body mass (not considered here.

We expected to find that intraspecific variation would consist on slight deviations of the average patterns. We did so for duration of development; however, for survival, clear antagonistic responses were restricted to larvae originating from five females; some showed either no effects or high sensitivity to low salinity. Such responses may reflect genetic variation as well as parental effects. 
Moksnes et al. (2014) also reported important variation in larval behavioural traits in the same region than our study; they attributed such variation to gene flow from the northern North Sea. However, for gene flow to explain increased tolerance to low salinity, our local population would need to be connected to those influenced by the Baltic Sea; models (Moksnes et al. 2014) as well as genetic data (Roman and Palumbi 2004; Domingues et al. 2010) speak against this hypothesis. Instead, the observed variation may be explained through important gene flow with populations from NW European Seas (Roman and Palumbi 2004). Alternatively, the observed variation might originate in fluctuations in the temperature and salinity experienced by parents or embryos (Laughlin \& French 1989, Giménez and Anger 2001; González-Ortegón and Giménez 2014). Such a mechanism may point towards potential population bottlenecks, caused by a suboptimal maternal environment. Overall, the large magnitude of intraspecific variation found here points toward the necessity to find the underlying causes.

Through correlation analysis, we attempted to find some indications as to which traits or processes may explain the observed levels of intraspecific variation. First, we reasoned that if variation in the same set of traits was responsible for the variation in performance at all temperature-salinity combinations, we would expect high correlations in performance among such conditions; in addition trade-offs may be reflected in negative correlations in physiological tolerance to opposite extreme conditions or to extreme conditions in different environmental variables. We found that survival was highly and positively correlated across temperatures in larvae reared in seawater and at salinity 25 suggesting that performance at those conditions is based on a shared set of physiological traits. We also found that correlations were low for survival of larvae reared at $20 \mathrm{vs}$. other salinities, suggesting that the traits driving tolerance to low salinity differed from those driving survival at other conditions. Second, we tested if variation in larval reserves at hatching would predict variation in survival and development. Following theory (Kindsvater and Otto 2014) and previous results (Giménez and Anger 2003; González-Ortegón and Giménez 2014), we expected that larger offspring size or biomass would result in better performance (i.e. higher survival rates and shorter duration of development) but we found no such evidence for survival and only weak evidence for duration of development. Correlations between duration of development and nutritional reserves were significant only at the lowest salinity and for percent Carbon. Although such pattern would be consistent with the hypothesis that different set of traits govern performance at low vs. moderate-high salinities, such relationships were weak. Intraspecific variation in performance may be driven either by concomitant variation in traits that are relevant to stressor tolerance such as those driving physiological repair mechanisms or osmoregulation (Lucu and Towle 2003; Cieluch et al. 2004). 
Overall, our data lead us to the following main conclusions and hypothesis. First, that it is important to be aware of potentially intraspecific variation in response of organisms to climate driven environmental factors; as implied in Appelbaum et al. (2014) the average response will not tell the whole picture. Correlation analysis suggest that traits driving variation in tolerance to low salinity are not the same as those driving variation in survival at high salinities. Based on previous studies (Giménez and Anger 2003, G. Torres unpubl. data for C. maenas larvae) we hypothesise that environmental conditions experienced by embryos are a likely driver of some of the observed variations, although we do not discard other sources. Understanding such sources is a priority to predict the likely responses to climate change: variability originated in genetic diversity might lead to a form of storage effect (Bolnick et al. 2011) through selection and local adaptation to future thermal conditions. However, the same variability, when driven by a suboptimal maternal environment (e.g. unfavourable temperatures) might lead to population decline.

Authors' contributions: LG, SH and GT conceived the experiments. FS, RM and GT performed the experiments. FS and LG analysed the data. FS wrote the first draft as part of her doctoral dissertation. LG and GT wrote the final manuscript. All authors improved the final manuscript.

All applicable international, national, and/or institutional guidelines for the care and use of animals were followed.

Funding: This work was funded by the Deutsche Forschungsgemeinschaft (DFG, Research Training Group 2010: RESPONSE programme, work-package B3) and involved a collaboration between the working groups of S. Harzsch (Greifswald University, Germany), G. Torres (AWIHelgoland, Germany) and L. Giménez (Bangor University, UK and AWI-Helgoland, Germany).

The funding body did not influence the design of the study and collection, analysis, and interpretation of data nor the writing of the manuscript.

Conflicts of interest: The authors declare that they have no conflicts of interests.

Compliance with Ethical Standards: The research presented in this paper complies with the guidelines from the directives 2010/63/EU of the European parliament and of the Council of $22^{\text {nd }}$ September 2010 on the protection of animals used for scientific purposes.

\section{References}


Anger K, Spivak E, Luppi T (1998) Effects of reduced salinities on development and bioenergetics of early larval shore crab, Carcinus maenas. J Exp Mar Biol Ecol 220:287-304.

Appelbaum SL, Pan TCF, Hedgecock D, Manahan DT (2014) Separating the nature and nurture of the allocation of energy in response to global change. Integr Comp Biol 54:284-295.

Bils F, Kanstinger P, Kloppmann MHF, Peck MA (2012) Habitat partitioning by fish larvae among coastal, offshore and frontal zones in the southern North Sea. Aquatic Biology 15:237-250.

Bolker BM, Brooks ME, Clark CJ, Geange SW, Poulsen JR, Stevens MHH, White JSS (2009) Generalized linear mixed models: a practical guide for ecology and evolution. Trends Ecol Evol 24:127-135.

Bolnick DI, Amarasekare P, Araújo MS, Bürger R, Levine JM, Novak M, Rudolf VHW, Schreiber SJ, Urban MC, Vasseur D (2011) Why intraspecific trait variation matters in community ecology. Trends Ecol Evol. 26(4):183-192.

Boyd PW, Collins S, Dupont S, Fabricius K, Gattuso J-P, Havenhand J, Hutchins DA, Riebesell U, Rintoul MS, Vichi M, Biswas H, Ciotti A, Gao K, Gehlen M, Hurd CL, Kurihara H, McGraw CM, Navarro JM, Nilsson GE, Passow U, Pörtner H-O (2018) Experimental strategies to assess the biological ramifications of multiple drivers of global ocean change - a review. Global Change Biol 24: 2239-2261.

Brierley AS, Kingsford MJ (2009) Impacts of climate change on marine organisms and ecosystems. Curr Biol 19:R602-R614.

Carter HA, Ceballos-Osuna L, Miller NA, Stillman JH (2013) Impact of ocean acidification on metabolism and energetics during early life stages of the intertidal porcelain crab Petrolisthes cinctipes. J Exp Biol 216:1412-1422.

Campbell PJ, Jones MB (1989) Osmoregulation of the estuarine prawn Palaemon longirostris (Caridea: Palaemonidae). J Mar Biol Assoc UK 69:261-272.

Charmantier G (1998) Ontogeny of osmoregulation in crustaceans: a review. Invertebr Reprod Dev 33(2-3):177-190.

Christidis N, Jones GS, Stott PA (2015) Dramatically increasing chance of extremely hot summers since the 2003 European heatwave. Nature Climate Change 5:46-50.

Cieluch U, Anger K, Aujoulat F, Buchholz F, Charmantier-Daures M, Charmantier G (2004) Ontogeny of osmoregulatory structures and functions in the green crab Carcinus maenas (Crustacea, Decapoda). J Exp Biol 207:325-336. 
Compton TJ, Leathwick JR, Inglis GJ. (2010) Thermogeography predicts the potential global range of the invasive European green crab (Carcinus maenas). Divers Distributions 16:243-55.

Côté IM, Darling ES, Brown CJ (2016) Interactions among ecosystem stressors and their importance in conservation. Proc R Soc Lond B 283:2015-2592.

Cowgill UM, Williams DM, Esquivel JB (1984) Effects of maternal nutrition on fat-content and longevity of neonates of Daphnia magna. J Crustacean Biol 4:173-190.

Cowen RK, Sponaugle S (2009) Larval dispersal and marine population connectivity. Annu Rev Mar Sci 1:443-466.

Crain CM, Kroeker K, Halpern BS (2008) Interactive and cumulative effects of multiple human stressors in marine systems. Ecol Lett 11:1304-1315.

Dawirs RR (1985) Temperature and larval development of Carcinus maenas (Decapoda) in the laboratory; predictions of larval dynamics in the sea. Mar Ecol Prog Ser 24:297-302.

De Laender F (2018) Community-and ecosystem- level effects of multiple environmental change drivers: Beyond null model testing. Global Change Biol 24:5021-5030.

deRivera CE, Hitchcock NG, Teck SJ, Stevens BP, Hines AH, Ruiz GM (2007) Larval development rate predicts range expansion of an introduced crab. Mar Biol 150:1275-1288.

Denny, M. (2017) The fallacy of the average: on the ubiquity, utility and continuing novelty of Jensen's inequality. J Exp Biol 220, 139-146.

Domingues CP, Creer S, Taylor MI, Queiroga H, Carvalho GR (2010) Genetic structure of Carcinus maenas within its native range: larval dispersal and oceanographic variability. Mar Ecol Prog Ser 410:111-123.

Doney SC, Ruckelshaus M, Duffy JE, Barry JP, Chan F, English CA, Galindo HM, Grebmeier JM, Hollowed AB, Knowlton N, Polovina J, Rabalais NN, Sydeman WJ, Talley LD (2012) Climate change impacts on marine ecosystems. Annu Rev Mar Sci 4:11-37.

Donelson JM, Munday PL, McCormick MI, Nilsson GE (2011) Acclimation to predicted ocean warming through developmental plasticity in a tropical reef fish. Global Change Biol 17:17121719.

Durrant HMS, Clark GF, Dworjanyn SA, Byrne M Johnston EL (2013). Seasonal variation in the effects of ocean warming and acidification on a native bryozoan, Celleporaria nodulosa. Mar Biol 160:1903-1911. 
Flügel H (1963) Elektrolytregulation und Temperatur bei Crangon crangon L. und Carcinus maenas L. Kiel Meeresforsch 19:189-195.

Folt CL, Chen CY, Moore MV, Burnaford J (1999) Synergism and antagonism among multiple stressors. Limnol Oceanogr 44:864-877.

530 Fregly MJ (2011) Adaptations: some general characteristics. Comp Physiol 14:3-15.

531 Galic N, Sullivan LL, Grimm V, Forbes VE (2018) When things don't add up: quantifying impacts of multiple stressors from individual metabolism to ecosystem processing. Ecol Lett 21(4):568577.

Galecki A, Burzykowski T (2013) Linear Mixed-Effect Models Using R. Springer, New York 245273.

Gattuso JP, Hansson L, 2009. Ocean Acidification. Oxford.

Giménez L, Anger K (2001) Relationships among salinity, egg size, embryonic development, and larval biomass in the estuarine crab Chasmagnathus granulata Dana, 1851. J Exp Mar Biol Ecol 260:241-257.

Giménez L, Anger K (2003) Larval performance in an estuarine crab, Chasmagnathus granulata, is a consequence of both larval and embryonic experience. Mar Ecol Prog Ser 249:251-264.

González-Ortegón E, Giménez L (2014) Environmentally mediated phenotypic links and performance in larvae of a marine invertebrate. Mar Ecol Prog Ser 502:185-195.

Gunderson AR, Armstrong EJ, Stillman JH (2016) Multiple stressors in a changing world: the need for an improved perspective on physiological responses to the dynamic marine environment. Annu

Harvey BP, Gwynn-Jones D, Moore PJ (2013) Meta-analysis reveals complex marine biological responses to the interactive effects of ocean acidification and warming. Ecol Evol 3(4):1016-1030.

Hoegh-Guldberg O, Bruno JF (2010) The impact of climate change on the world's marine ecosystems. Science 328:1523-1528.

IPCC (2014) Climate Change 2014: Synthesis report. Contribution of working groups I, II and III to the fifth assessment report of the Intergovernmental Panel on Climate Change [Core Writing Team, R.K. Pachauri and L.A. Meyer (eds.)]. IPCC, Geneva, Switzerland, 151pp.

Janas U, Spicer J (2008) Does the effect of low temperature on osmoregulation by the prawn Palaemon elegans Rathke, 1837 explain winter migration offshore? Mar Biol 153(5):937-943. 
Kindsvater HK, Otto SP (2014) The evolution of offspring size across life-history stages. Am Nat 184:543-555.

Kinne O (1971). Salinity. In: Marine ecology. A comprehensive, integrated treatise on life in oceans and coastal waters. Wiley: London.

Kroeker KJ, Kordas RL, Crim R, Hendriks IE, Ramajo L, Singh GS, Duarte CM, Gattuso J-P (2013) Impacts of ocean acidification on marine organisms: quantifying sensitivities and interaction with warming. Global Change Biol 19:1884-1896.

Lange R, Marshall D (2017) Ecologically relevant levels of multiple, common marine stressors suggest antagonistic effects. Sci Rep 7(1):6281.

Lucu C, Towle DW (2003) $\mathrm{Na}^{+}-\mathrm{K}^{+}$-ATPase in gills of aquatic crustacea. Comp Biochem Physiol A Physiol 135:195-214.

Marshall DJ, Allen RM, Crean AJ (2008) The ecological and evolutionary importance of maternal effects in the sea. Oceanogr Mar Biol Annu Rev 46:203-262.

Meyer EMI, Pohlmann T, Weisse R (2011) Thermodynamic variability and change in the North Sea (1948-2007) derived from a multidecadal hindcast. J Mar Syst 86:35-44.

Moksnes P-O, Corell H, Tryman K, Hordoir R, Jonsson PR (2014) Larval behavior and dispersal mechanisms in shore crab larvae (Carcinus maenas): Local adaptations to different tidal environments? Limnol Oceanogr 59:588-602.

Nagaraj M (1993) Combined effects of temperature and salinity on the zoeal development of the green crab, Carcinus maenas (Linnaeus, 1758) (Decapoda, Portunidae). Sci Mar 57(1) 1-8.

Nasrolahi A, Pansch C, Lenz M, Wahl M (2012) Being young in a changing world: how temperature and salinity changes interactively modify the performance of larval stages of the barnacle Amphibalanus improvisus. Mar Biol 159(2):331-340.

O’Connor MI, Bruno JF, Gaines SD, Halpern BS, Lester SE, Kinlan BP, Weiss JM (2007) Temperature control of larval dispersal and the implications for marine ecology, evolution, and conservation. Proc Natl Acad Sci 104:1266-1271.

Palumbi SR (2003) Population genetics, demographic connectivity, and the design of marine reserves. Ecol Appl 13(1):S146-S158.

Pandori, LLM, Sorte CJB (2019). The weakest link: sensitivity to climate extremes across life stages of marine invertebrates. Oikos, 128:621-629. 
Parker LM, O'Connor WA, Byrne M, Coleman RA, Virtue P, Dove M et al. (2017) Adult exposure to ocean acidification is maladaptive for larvae of the Sydney rock oyster Saccostrea glomerata in the presence of multiple stressors. Biol Lett 13.

Pechenik JA (1987) Environmental influences on larval survival and growth. In: Giese AC and. Pearse JS (eds.) Reproduction of Marine Invertebrates, Vol. 9, Blackwell Scientific, NY, pp 551608.

Philippart CJM, Anadón R, Danovaro R, Dippner JW, Drinkwater KF, Hawkins SJ, Oguz T, O‘Sullivan G, Reid PC (2011) Impacts of climate change on European marine ecosystems: Observations, expectations and indicators. J Exp Mar Biol Ecol 400:52-69.

Piggott JJ, Townsend CR, Matthaei CD (2015) Reconceptualizing synergism and antagonism among multiple stressors. Ecol Evol 5(7):1538-1547.

Pinheiro J, Bates D, DebRoy S, Sarkar D and R Core Team (2018). nlme: Linear and Nonlinear Mixed Effects Models. R package version 3.1-137 https://CRAN.R-project.org/package=nlme.

Pond D, Harris R, Head R, Harbour D (1996) Environmental and nutritional factors determining seasonal variability in the fecundity and egg viability of Calanus helgolandicus in coastal waters off Plymouth, UK. Mar Ecol Progr Ser 143:45-63.

Pörtner HO (2010) Oxygen- and capacity-limitation of thermal tolerance: a matrix for integrating climate-related stressor effects in marine ecosystems. J Exp Biol 213:881-893.

Przeslawski R, Byrne M, Mellin C (2015) A review and meta-analysis of the effects of multiple abiotic stressors on marine embryos and larvae. Global Change Biol 21(6):2122-2140.

Roman J, Palumbi SR (2004) A global invader at home: population structure of the green crab, Carcinus maenas, in Europe. Mol Ecol 13:2891-2898.

Robins PE, Skov MW, Lewis MJ, Giménez L, Davies AG, Malham SK, Neill SP, McDonald JE, Whitton TA, Jackson SE, Jago CF (2015) Impact of climate change on UK estuaries: a review of past trends and potential projections. Estuar Coastal Shelf Sci 169:119-135.

Shama LNS, Strobel A, Mark FC, Wegner KM (2014) Transgenerational plasticity in marine sticklebacks: maternal effects mediate impacts of a warming ocean. Funct Ecol 28:1482-1493.

Schäfer RB, Piggott JJ (2018) Advancing understanding and prediction in multiple stressor research through a mechanistic basis for null models. Global Change Biol 24(5):1817-1826.

Schindler DE, Armstrong JB, Reed TE (2015). The portfolio concept in ecology and evolution. Frontiers Ecol Environ 13:257-263. 
Schrum C, Lowe J, Meier HEM, Grabemann I, Holt J, Mathis M, Pohlmann T, Skogen MD, Sterl A, Wakelin S (2016) Projected Change-North Sea. In: Quante M, Colijn F (eds). North Sea Region Climate Change Assessment. Regional Climate Studies, Springer Open:175-217.

Sokolova IM, Frederich M, Bagwe R, Lannig G, Sukhotin AA (2012) Energy homeostasis as an integrative tool for assessing limits of environmental stress tolerance in aquatic invertebrates. Mar Environ Res 79:1-15.

Spitzner F, Meth R, Krüger C, Nischik E, Eiler S, Sombke A, Torres G, Harzsch S (2018) An atlas of larval organogenesis in the European shore crab Carcinus maenas L. (Decapoda, Brachyura, Portunidae). Front Zool 15:27.

Torres G, Giménez L, Pettersen AK, Bue M, Burrows MT, Jenkins SR (2016) Persistent and contextdependent effects of the larval feeding environment on post-metamorphic performance through the adult stage. Mar Ecol Prog Ser 545:147-160.

Torres G, Spitzner F, Harzsch S, Giménez L (2019) Ecological developmental biology and global ocean change: brachyuran crustacean larvae as models. In: G. Fusco (ed.) Perspectives in evolutionary and developmental biology. Padova University Press, Padova.

Uller T, Nakagawa S, English S (2013) Weak evidence for anticipatory parental effects in plants and animals. J Evol Biol 26:2161-2170.

Wiltshire KH, Kraberg A, Bartsch I, Boersma M, Franke H.-D, Freund J, Gebür C, Gerdts G, Stockmann K, Wichels A (2010) Helgoland Roads, North Sea: 45 Years of Change. Estuaries Coasts 33:295-310.

Zuur A, Ieno E, Walker N, Savaliev A, Smith G (2009) Mixed effect models and extensions in ecology with R. New York: Springer. 
641 Figure 1. Carcinus maenas. Effects of temperature and salinity on average survival and duration 642 of development from hatching to the Zoea IV. Cumulative survival to Zoea II (a), Zoea III (b) and 643 Zoea IV (c); cumulative duration of development to Zoea II (e), Zoea III (f) and Zoea IV (g). Bars 644 indicate standard errors among larvae produced by different females ( $\mathrm{n}=10$ for zoeal survival and 645 development).

646 Figure 2. Carcinus maenas. Relationships between average duration of development (from 647 hatching to each zoeal stage) and temperature, plotted according to the Arrhenius transform (f), for 648 larvae reared at different salinities. Bars indicate standard errors among larvae produced by different 649 females $(n=10)$.

650 Figure 3. Carcinus maenas. Variability in the effects of temperature and salinity on average 651 survival (top panels) and duration of development (bottom panels) from hatching to the Zoea II. Each 652 panel depicts responses observed in larvae produced by a single female (numbered from 1 to 10). 653 Bars indicate standard errors among replicate groups of larvae produced by each separate female $654(\mathrm{n}=4)$. Symbols as in Figure 1. Notice for instance the differences in the survival patterns between 655 larvae from female 1 (antagonistic), 3 (no effect) and 9 (overall low larval survival). Data 656 corresponding to subsequent stages are given in Figure S2.

657 Figure 4. Carcinus maenas. Surface plot of correlations between average survival proportions in 658 larvae reared in seawater (32) and at $15^{\circ} \mathrm{C} v s$. those reared at other combinations of temperature and 659 salinity. The average survival proportion was estimated from hatching to moulting to stages II, III 660 and IV in larvae produced by 10 females reared at 12 salinity-temperature combinations. Surfaces 661 were computed as a bi-cubic spline smooth. The full correlation matrix is given in Table S1. 
665 Table 1. Carcinus maenas. Summary of model selection (AIC scores) for mixed models evaluating 666 the effect of temperature and salinity on cumulative survival and duration of development of larvae 667 from hatching to Zoea II, III and IV. Models with lowest AIC were retained; model selection was 668 carried out through Restricted maximum likelihood fitting (REML) for the random structure and with 669 maximum likelihood for the fixed structure (ML).

670

\begin{tabular}{ccccccccccccccc}
\hline & \multicolumn{3}{c}{ Survival } & \multicolumn{4}{c}{ Duration of development } \\
\hline Scale: & \multicolumn{3}{c}{ Logistic } & \multicolumn{2}{c}{ Logarithmic } & & Raw & & Logarithmic \\
\hline Random & ZII & ZIII & ZIV & ZII & ZIII & ZIV & ZII & ZIII & ZIV & ZII & ZIII & ZIV \\
\hline F:S:T (full) & 1231 & 1220 & 1227 & 709 & 801 & 916 & 1331 & 1627 & 1854 & -665 & -828 & -890 \\
F:T & 1369 & 1379 & 1402 & 836 & 989 & 1091 & 1401 & 1691 & 1918 & -540 & -741 & -778 \\
F:S & 1321 & 1336 & 1336 & 843 & 960 & 1044 & 1350 & 1674 & 1909 & -608 & -785 & -802 \\
F & 1424 & 1431 & 1434 & 933 & 1054 & 1133 & 1428 & 1731 & 1970 & -518 & -721 & -728 \\
\hline Fixed terms & & & & & & & & & & & \\
T:S & 1222 & 1211 & 1218 & 685 & 781 & 899 & 1322 & 1630 & 1860 & -725 & -892 & -957 \\
T+S & 1258 & 1241 & 1247 & 726 & 816 & 923 & 1391 & 1682 & 1926 & -709 & -882 & -940 \\
\hline
\end{tabular}


Table 2. Carcinus maenas. Parameter estimates and significance of polynomial regression explaining the effect of temperature and salinity through the universal temperature dependence of metabolic rates (UTD). Temperature is included in the UTD through the Arrhenius equation with known parameters, which here is contained in the term $f$. Salinity $(\mathrm{StS})$ is expressed with respect to the control ( $\mathrm{StS}=0$ for larvae reared under control salinity). Parameter estimates correspond to the polynomial fitting in the raw form; significance $(* p<0.05$, ns: non-significant) was evaluated using 679 the orthogonal polynomial approach. The models fitted at each salinity are given at the bottom of the 680 table by setting the non-significant parameters to zero. Notice that under control conditions, $\mathrm{StS}=0$, 681 all terms containing StS vanish; for other salinities, the linear terms are recalculated from the 682 parameter estimates, with $f=0.64 /\left[8.62 \cdot 10^{-5} \cdot(\mathrm{T}+273)\right]$.

683

\begin{tabular}{|c|c|c|c|c|c|c|}
\hline Random & \multicolumn{2}{|c|}{ Zoea II } & \multicolumn{2}{|l|}{ Zoea III } & \multicolumn{2}{|c|}{ Zoea IV } \\
\hline Intercept & \multicolumn{2}{|c|}{0.2316} & \multicolumn{2}{|l|}{0.1715} & \multicolumn{2}{|c|}{0.1424} \\
\hline StS & \multicolumn{2}{|c|}{0.0083} & \multicolumn{2}{|l|}{0.0054} & \multicolumn{2}{|c|}{0.0064} \\
\hline Residual & \multicolumn{2}{|c|}{0.1236} & \multicolumn{2}{|l|}{0.1004} & \multicolumn{2}{|c|}{0.0099} \\
\hline Fixed & Estimate & SE & Estimate & SE & Estimate & SE \\
\hline Intercept & 242.10 & 88.44 & 352.70 & 44.45 & 232.72 & 71.01 \\
\hline$f$ & -19.51 & 6.97 & -28.22 & 3.50 & -18.77 & 5.59 \\
\hline $\mathrm{StS}$ & 24.10 & 11.12 & -0.14 & 0.08 & 22.98 & 9.10 \\
\hline$f^{2}$ & 0.40 & 0.14 & 0.57 & 0.07 & 0.38 & 0.11 \\
\hline$f: \mathrm{StS}$ & -1.91 & 0.88 & 0.01 & 0.0003 & -1.81 & 0.72 \\
\hline$f^{2}: \mathrm{StS}$ & 0.04 & 0.02 & & & 0.04 & 0.01 \\
\hline Control & $\operatorname{Ln}(D)=242$ & $40 f^{2}$ & $\begin{array}{l}\operatorname{Ln}(D)=353-28.2 \\
f^{2}\end{array}$ & $f+0.57$ & $\begin{array}{l}\operatorname{Ln}(D)=23 \\
f^{2}\end{array}$ & $f+0.38$ \\
\hline Salinity 25 & $\operatorname{Ln}(D)=410$ & $66 f^{2}$ & $\begin{array}{l}\operatorname{Ln}(D)=352-28.2 \\
f^{2}\end{array}$ & $f+0.57$ & $\begin{array}{l}\operatorname{Ln}(D)=39 \\
f^{2}\end{array}$ & $f+0.63$ \\
\hline Salinity 20 & $\operatorname{Ln}(D)=531$ & $85 f^{2}$ & $\begin{array}{l}\operatorname{Ln}(D)=351-28.1 \\
f^{2}\end{array}$ & $f+0.57$ & $\begin{array}{l}\operatorname{Ln}(D)=50 \\
f^{2}\end{array}$ & $f+0.81$ \\
\hline
\end{tabular}


688

689

690

691

692

693

694

695

696

697

698

699

700

701

702

703

704

705

706

(a) 1.0
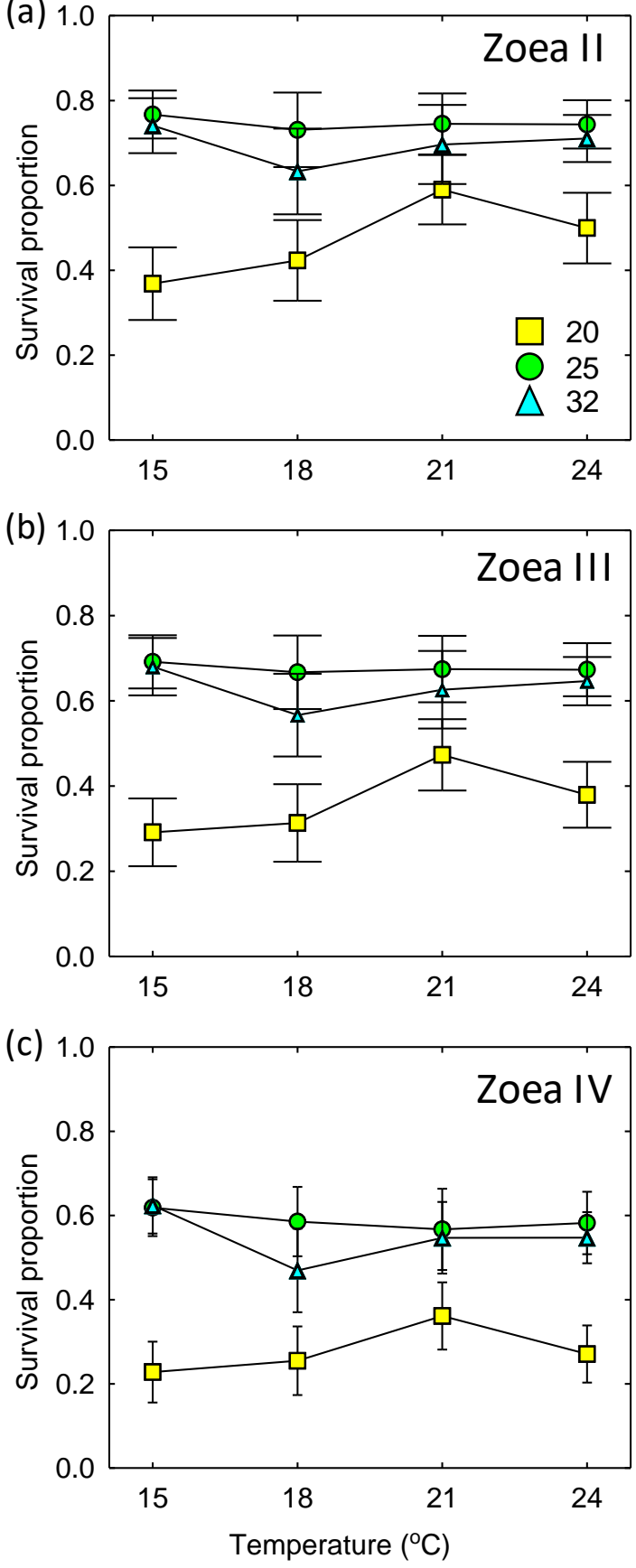
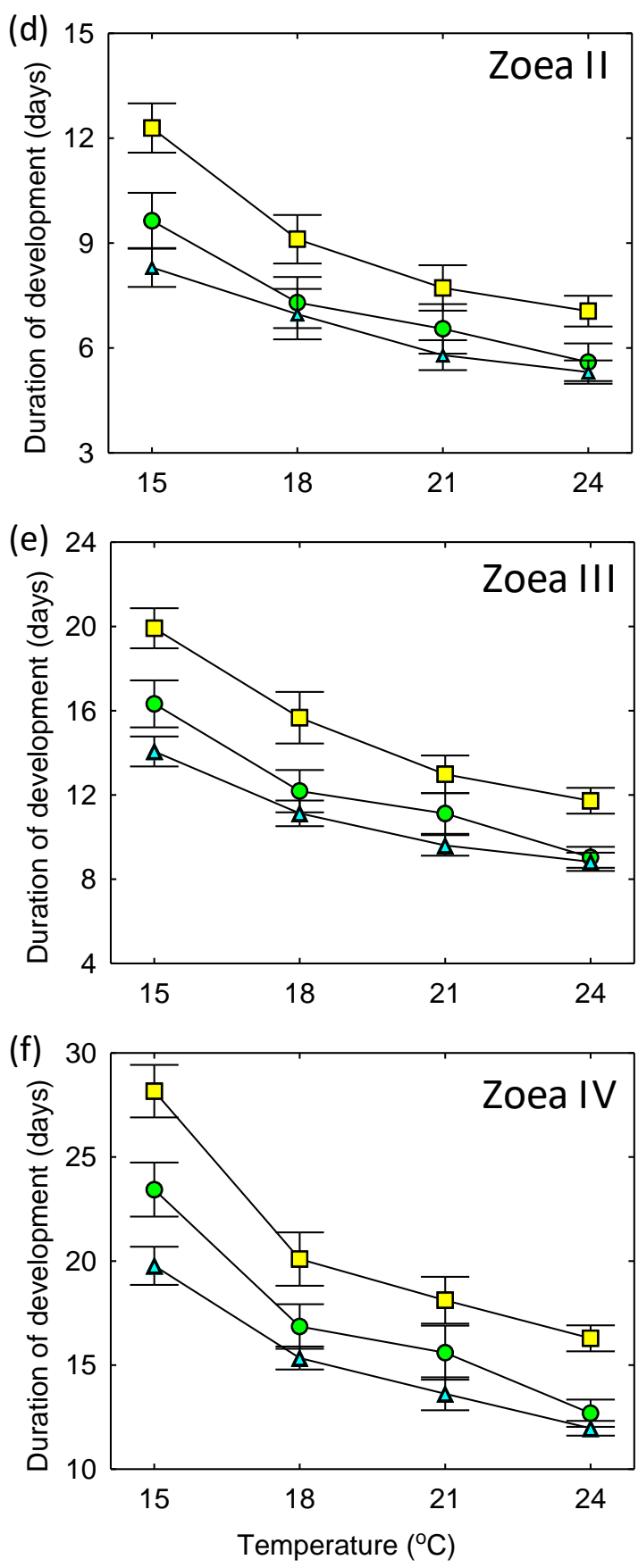

707

708

709 

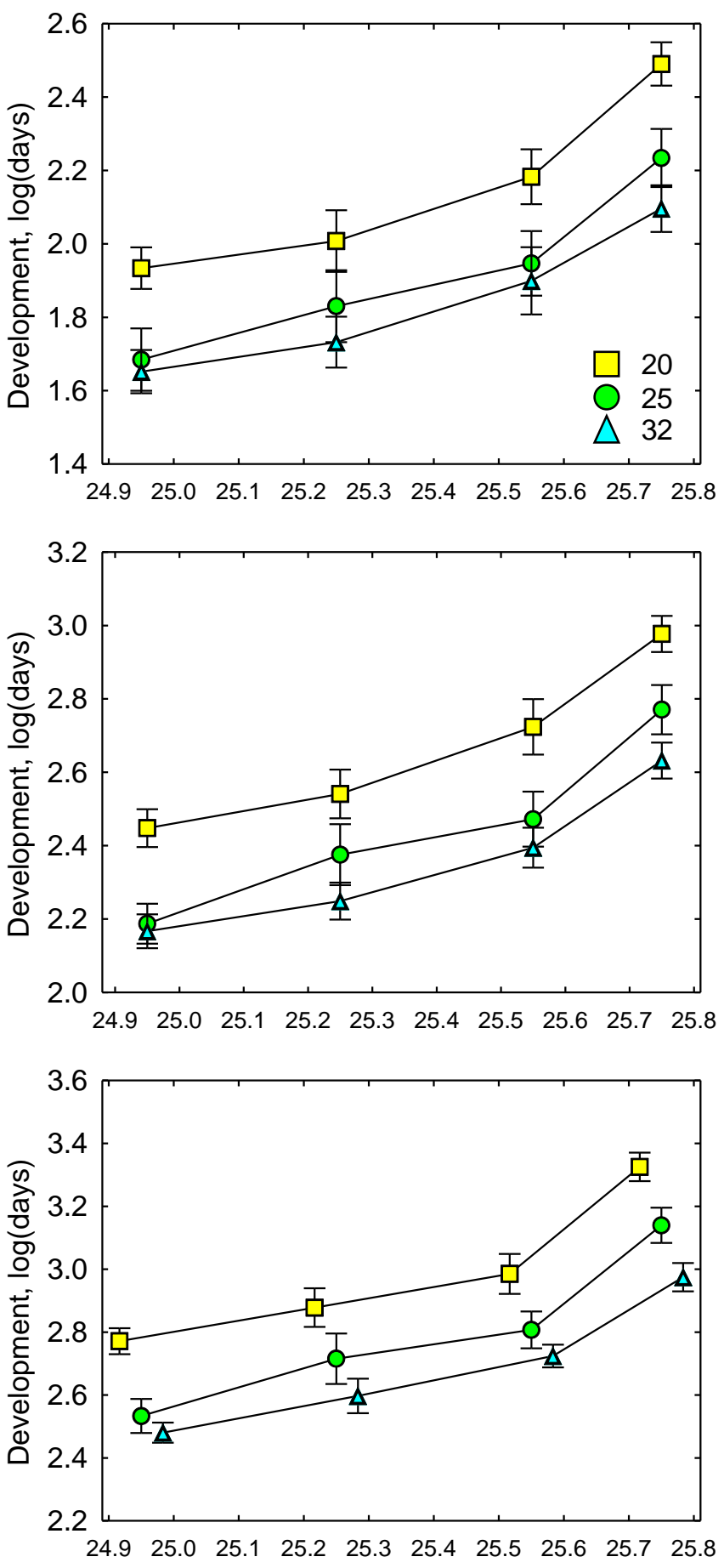
Survival

742

743

744

745

746

747

748

749
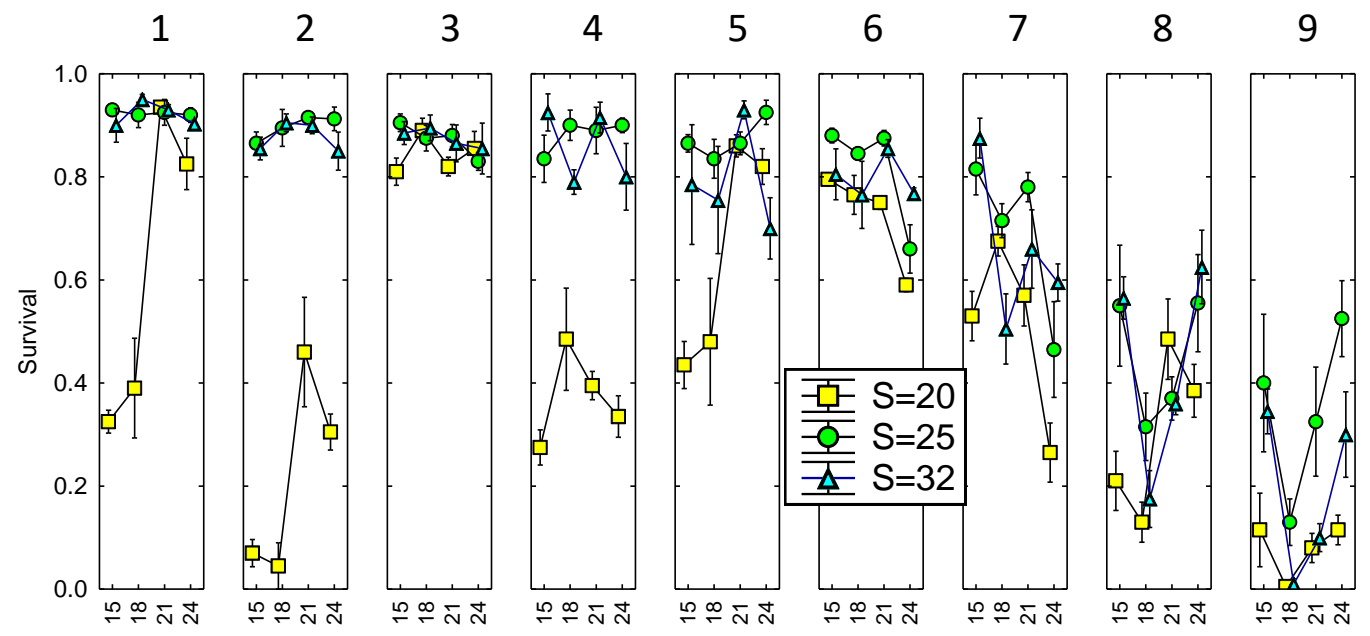

10

Temperature $\left({ }^{\circ} \mathrm{C}\right)$

Duration of development
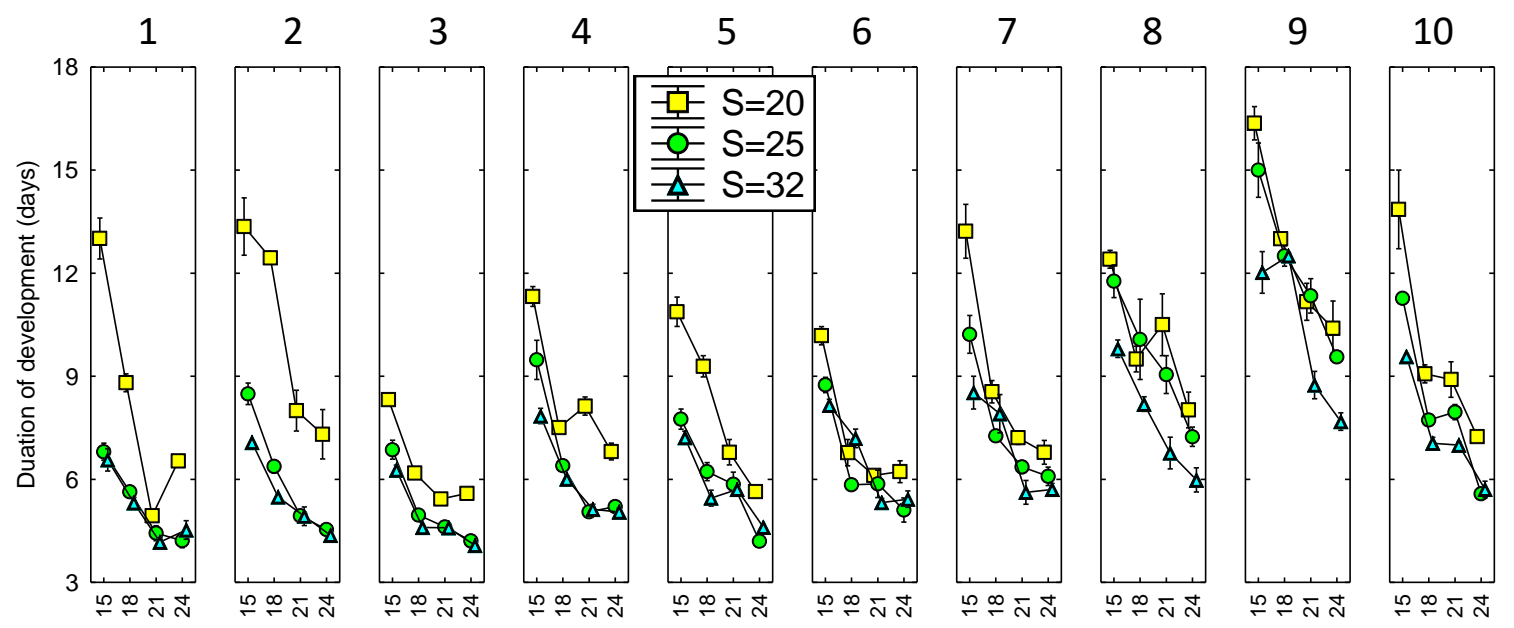

759

Temperature $\left({ }^{\circ} \mathrm{C}\right)$ 


\section{Zoea II}

770

771

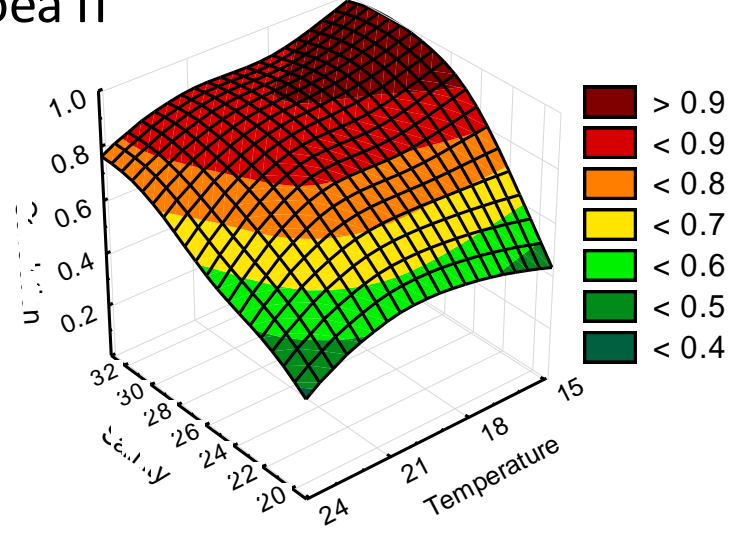

774

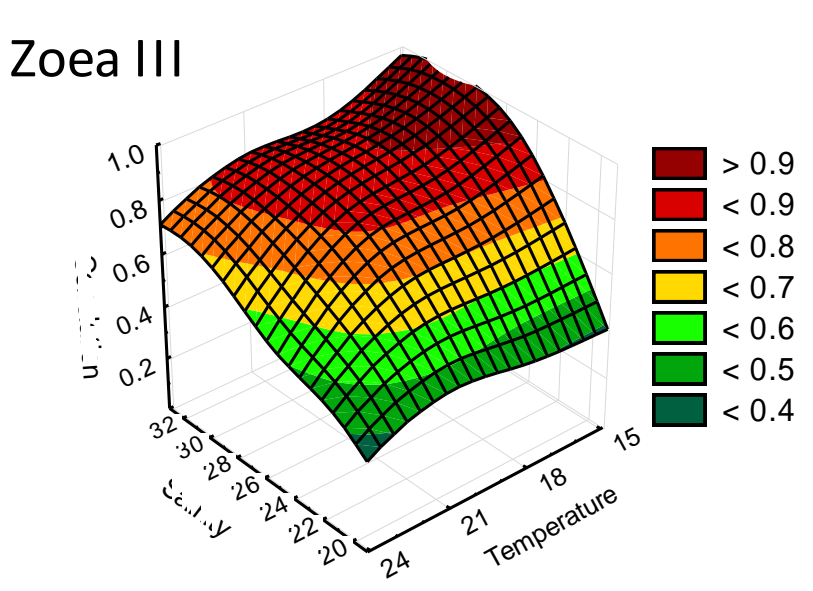

781

775

776

777

778

779

780

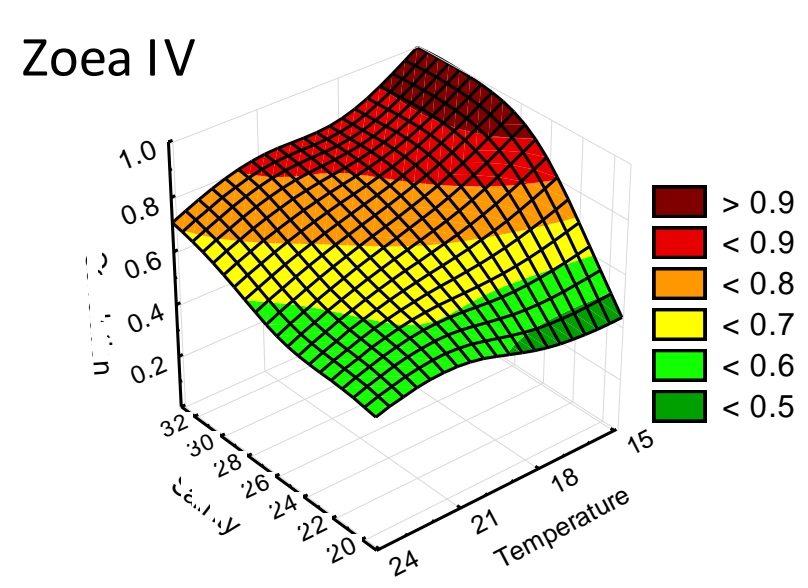

788

789

790

791

792

793

Figure 4

794 
$\underline{\text { Supplementary figures }}$
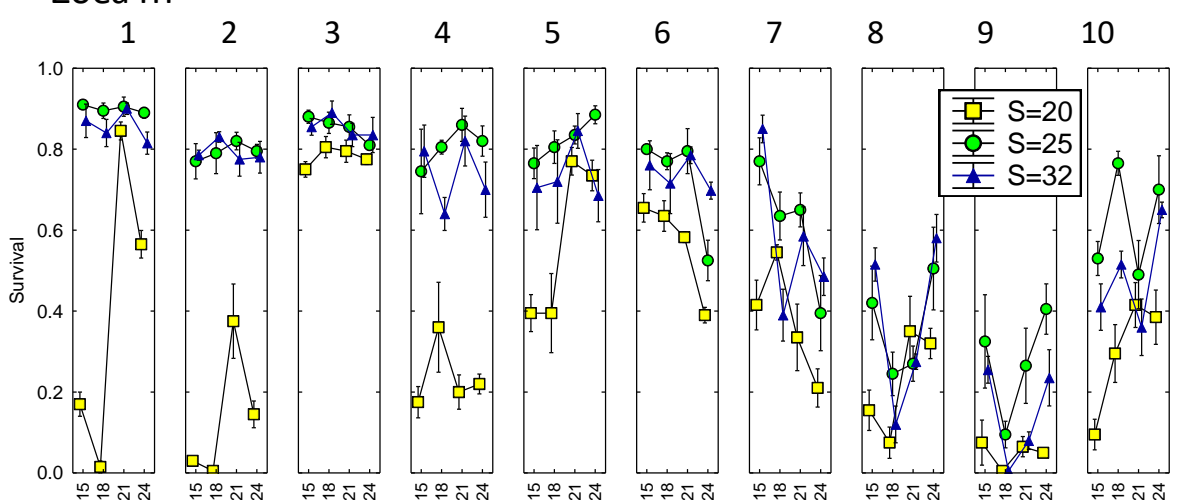

803

804

805
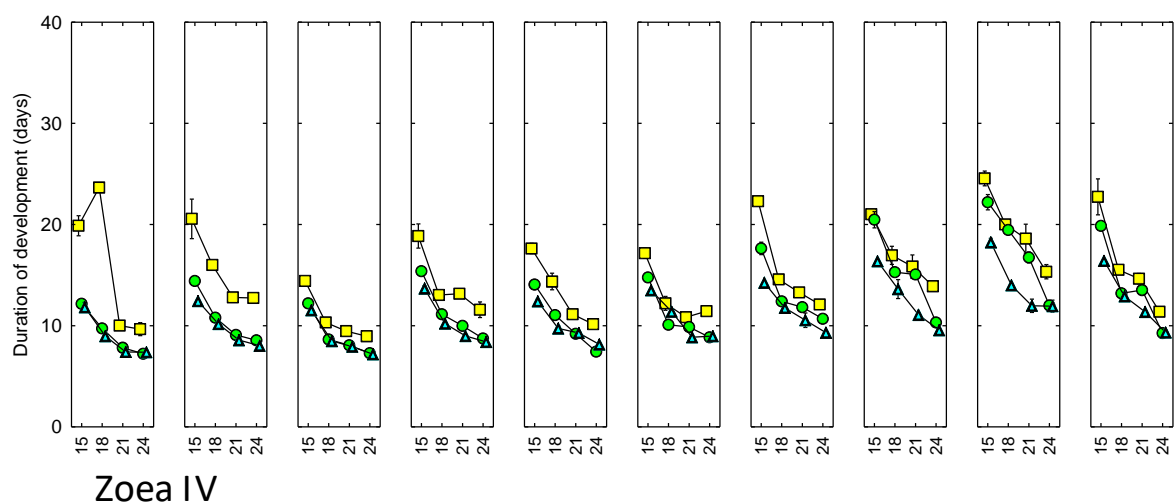

809

810
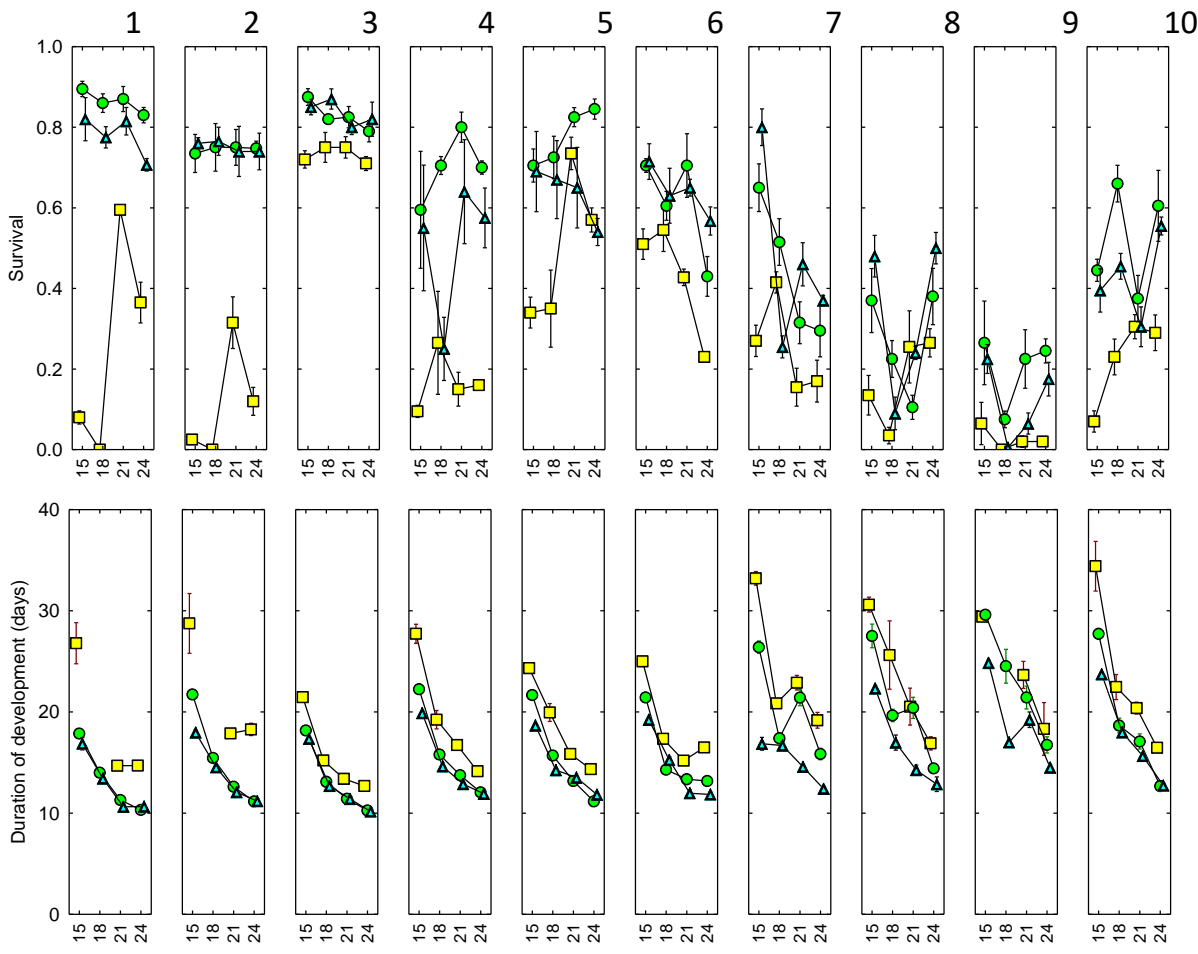

Figure S1. Carcinus maenas. Variability in the effects of temperature and salinity (S) on average survival and duration of development from hatching to the Zoea III and Zoea IV. Each panel depicts responses observed in larvae produced by a single female (numbered from 1 to 10). Bars indicate standard errors among replicate groups of larvae produced by each separate female $(n=4)$. 

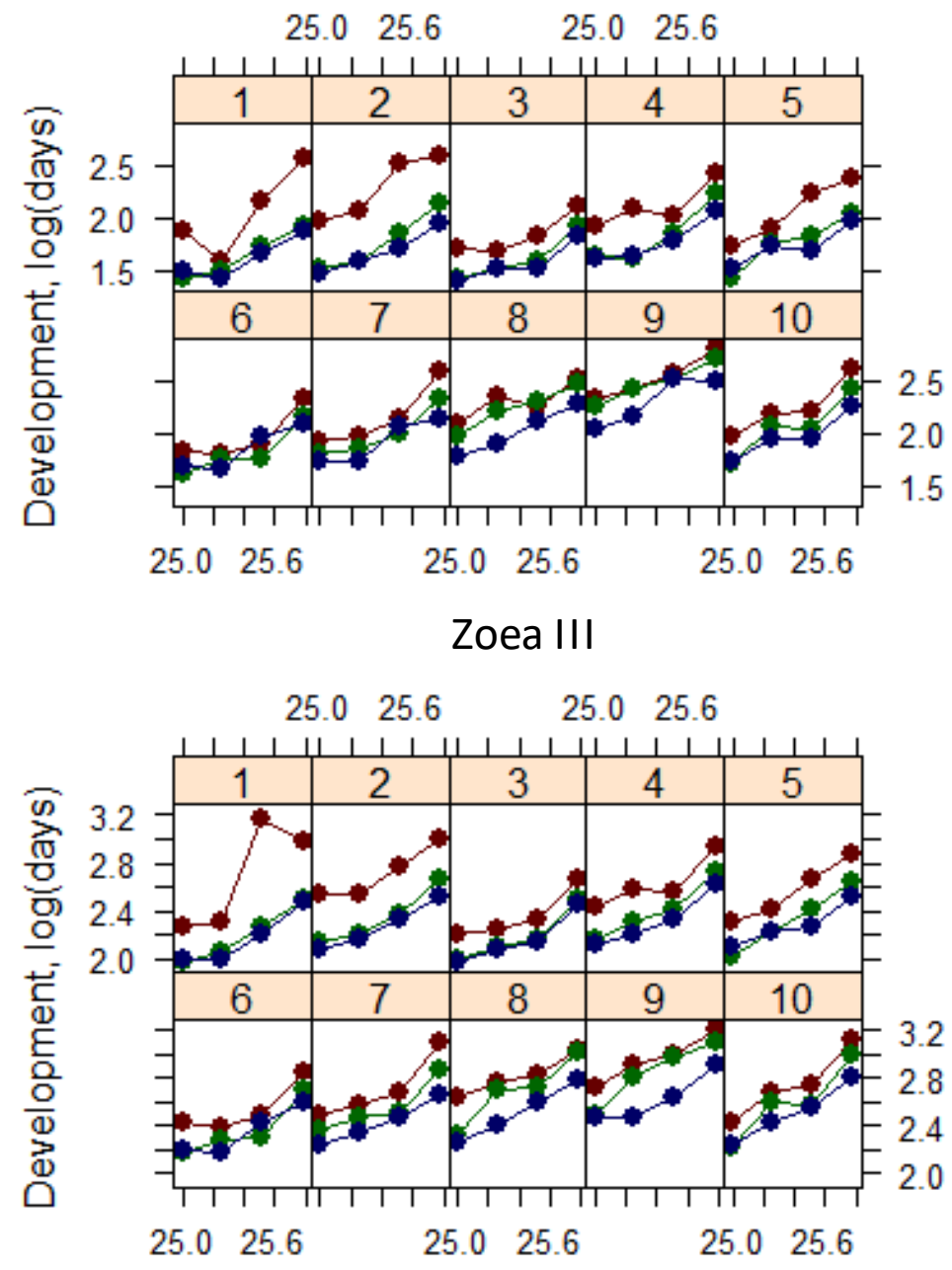

Figure S2. Carcinus maenas. Variability in the relationship between average duration of development and temperature plotted in the Arrhenius transform, $\mathrm{f}(\mathrm{T})$, for larvae produced by 10 females

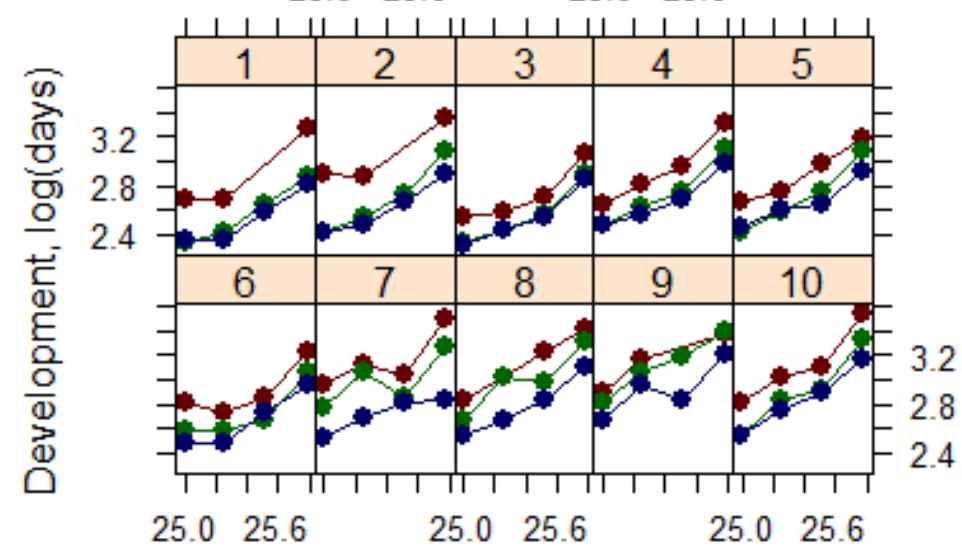

$f(T)$ (numbered from 1 to 10) and reared at three salinities. Symbols of different colours refer to different salinities as follows: red $=20$, green $=25$, blue $=32$. 


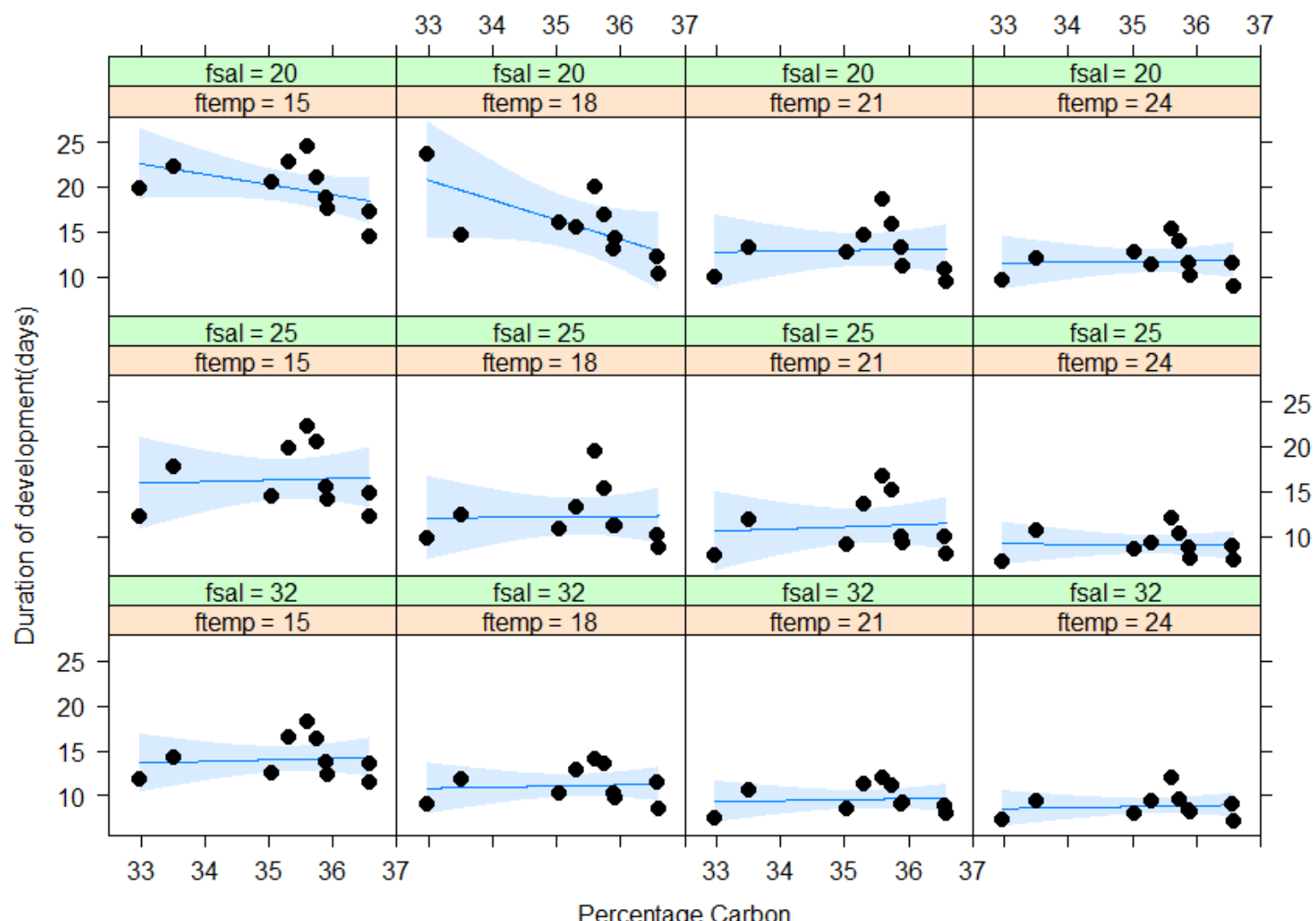

865 Figure S3. Carcinus maenas. Model fit for the relationship between average duration of larval 866 development to Zoea III and percent Carbon at hatching, in larvae produced by 10 females and reared 867 at twelve combinations of salinity (fsal) and temperature (ftemp). Black circles represent the partial 868 residuals and the blue areas represent the confidence bands. 


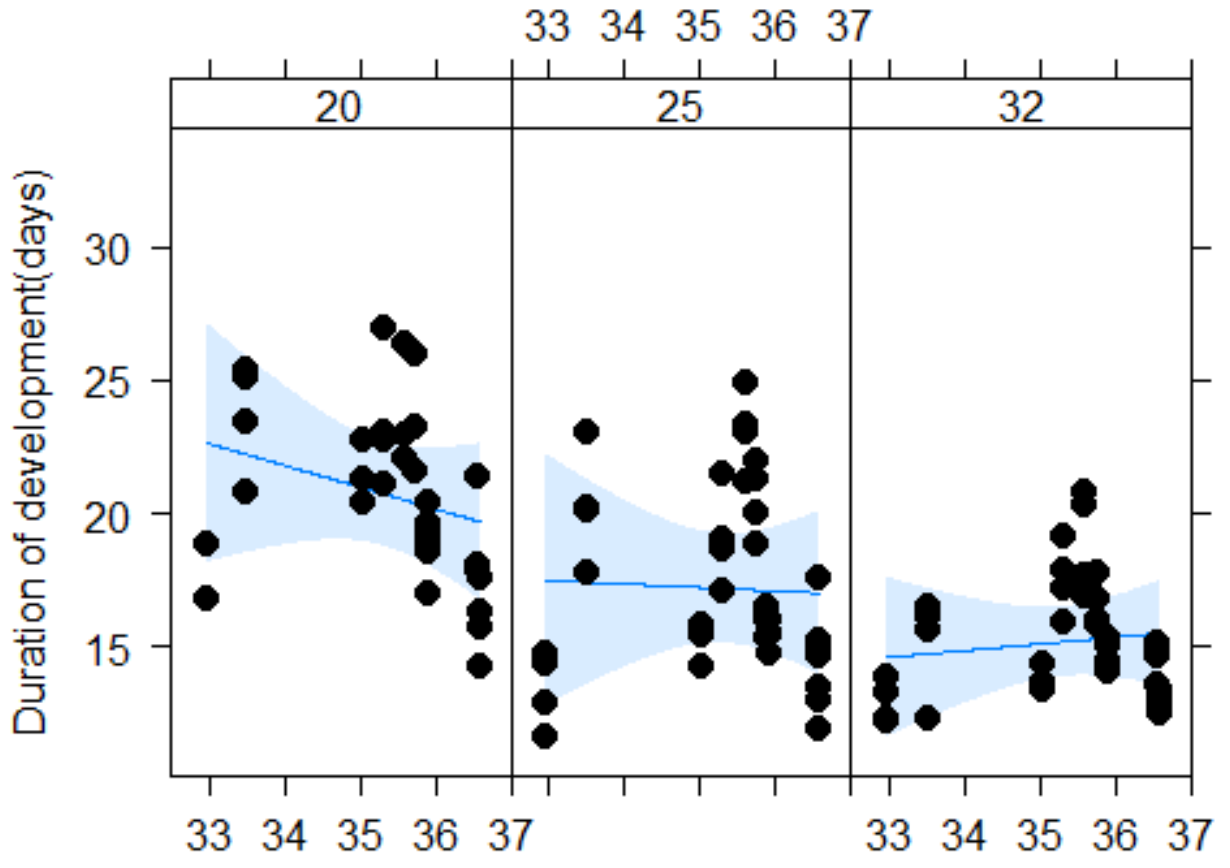

882 Figure S4. Carcinus maenas. Model fit for the relationship between average duration of larval 883 development to Zoea IV and percent Carbon at hatching, in larvae produced by 10 females reared at 884 three salinities $(20,25$ and 32). Black circles represent the partial residuals and the blue areas 885 represent the confidence bands.

886 
888

889

890

891

892

893

894

$\underline{\text { Supplementary table }}$

Table S1. Carcinus maenas. Correlation matrix for larval performance (survival: upper sector; duration of development: lower sector) to stages II, III and IV among larvae produced by 10 different females reared at 12 combinations of salinities $(\mathrm{S})$ and temperatures $(\mathrm{T})$. Significant correlations are in red. For duration of development to Zoea IV, the number of replicate units was 7 due to increased mortality at some temperature salinity combinations.

\begin{tabular}{|c|c|c|c|c|c|c|c|c|c|c|c|c|c|}
\hline \multicolumn{14}{|c|}{ Zoea II } \\
\hline \multirow[t]{2}{*}{$\mathrm{S}$} & \multirow{2}{*}{$\vec{T}$} & \multicolumn{4}{|c|}{20} & \multicolumn{4}{|c|}{25} & \multicolumn{4}{|c|}{32} \\
\hline & & 15 & 18 & 21 & 24 & 15 & 18 & 21 & 24 & 15 & 18 & 21 & 24 \\
\hline \multirow{4}{*}{20} & 15 & 1.00 & 0.92 & 0.61 & 0.55 & 0.56 & 0.33 & 0.46 & -0.04 & 0.51 & 0.38 & 0.45 & 0.30 \\
\hline & 18 & 0.83 & 1.00 & 0.64 & 0.57 & 0.64 & 0.55 & 0.58 & 0.08 & 0.58 & 0.50 & 0.54 & 0.42 \\
\hline & 21 & 0.67 & 0.64 & 1.00 & 0.92 & 0.78 & 0.67 & 0.67 & 0.48 & 0.61 & 0.71 & 0.72 & 0.71 \\
\hline & 24 & 0.84 & 0.76 & 0.85 & 1.00 & 0.63 & 0.58 & 0.55 & 0.59 & 0.43 & 0.65 & 0.61 & 0.64 \\
\hline \multirow{4}{*}{25} & 15 & 0.74 & 0.57 & 0.92 & 0.91 & 1.00 & 0.88 & 0.97 & 0.63 & 0.94 & 0.94 & 0.98 & 0.85 \\
\hline & 18 & 0.75 & 0.66 & 0.91 & 0.94 & 0.95 & 1.00 & 0.92 & 0.72 & 0.74 & 0.95 & 0.87 & 0.88 \\
\hline & 21 & 0.67 & 0.55 & 0.87 & 0.86 & 0.95 & 0.97 & 1.00 & 0.70 & 0.90 & 0.96 & 0.97 & 0.83 \\
\hline & 24 & 0.69 & 0.54 & 0.85 & 0.92 & 0.96 & 0.97 & 0.94 & 1.00 & 0.52 & 0.81 & 0.75 & 0.76 \\
\hline \multirow{4}{*}{32} & 15 & 0.72 & 0.52 & 0.88 & 0.88 & 0.99 & 0.95 & 0.97 & 0.95 & 1.00 & 0.83 & 0.92 & 0.77 \\
\hline & 18 & 0.72 & 0.55 & 0.77 & 0.90 & 0.94 & 0.93 & 0.92 & 0.97 & 0.95 & 1.00 & 0.94 & 0.92 \\
\hline & 21 & 0.67 & 0.56 & 0.87 & 0.83 & 0.95 & 0.93 & 0.98 & 0.90 & 0.96 & 0.89 & 1.00 & 0.86 \\
\hline & 24 & 71 & 0.48 & 0.79 & 0.87 & 0.96 & 0.92 & 0.94 & 0.96 & 0.98 & 0.99 & 0.92 & 1.00 \\
\hline \multicolumn{14}{|c|}{ Zoea III } \\
\hline$S$ & $\rightarrow$ & \multicolumn{4}{|c|}{20} & \multicolumn{4}{|c|}{25} & \multicolumn{4}{|c|}{32} \\
\hline$\downarrow$ & $\mathrm{T} \downarrow \rightarrow$ & 15 & 18 & 21 & 24 & 15 & 18 & 21 & 24 & 15 & 18 & 21 & 24 \\
\hline \multirow{5}{*}{20} & 15 & 1.00 & 0.91 & 0.55 & 0.61 & 0.53 & 0.36 & 0.42 & -0.01 & 0.49 & 0.40 & 0.45 & 0.31 \\
\hline & 18 & 0.60 & 1.00 & 0.36 & 0.49 & 0.48 & 0.44 & 0.40 & 0.00 & 0.44 & 0.38 & 0.40 & 0.28 \\
\hline & 21 & 0.84 & 0.32 & 1.00 & 0.92 & 0.71 & 0.67 & 0.63 & 0.61 & 0.57 & 0.73 & 0.69 & 0.73 \\
\hline & 24 & 0.76 & 0.30 & 0.92 & 1.00 & 0.55 & 0.56 & 0.50 & 0.61 & 0.41 & 0.60 & 0.56 & 0.63 \\
\hline & 15 & 0.81 & 0.23 & 0.95 & 0.84 & 1.00 & 0.89 & 0.96 & 0.60 & 0.95 & 0.91 & 0.96 & 0.79 \\
\hline \multirow[t]{4}{*}{25} & 18 & 0.80 & 0.41 & 0.96 & 0.88 & 0.93 & 1.00 & 0.91 & 0.75 & 0.76 & 0.95 & 0.89 & 0.86 \\
\hline & 21 & 0.77 & 0.26 & 0.95 & 0.85 & 0.99 & 0.95 & 1.00 & 0.72 & 0.87 & 0.94 & 0.98 & 0.79 \\
\hline & 24 & 0.79 & 0.20 & 0.90 & 0.90 & 0.91 & 0.89 & 0.91 & 1.00 & 0.47 & 0.79 & 0.72 & 0.80 \\
\hline & 15 & 0.78 & 0.26 & 0.94 & 0.82 & 0.99 & 0.93 & 0.99 & 0.89 & 1.00 & 0.78 & 0.91 & 0.72 \\
\hline \multirow[t]{3}{*}{32} & 18 & 0.77 & 0.22 & 0.90 & 0.85 & 0.97 & 0.88 & 0.97 & 0.90 & 0.96 & 1.00 & 0.93 & 0.91 \\
\hline & 21 & 0.76 & 0.12 & 0.90 & 0.76 & 0.98 & 0.89 & 0.96 & 0.87 & 0.95 & 0.94 & 1.00 & 0.83 \\
\hline & 24 & 0.76 & 0.26 & 0.91 & 0.87 & 0.92 & 0.95 & 0.93 & 0.93 & 0.93 & 0.91 & 0.89 & 1.00 \\
\hline \multicolumn{14}{|c|}{ Zoea IV } \\
\hline $\mathrm{S}$ & $\rightarrow$ & \multicolumn{4}{|c|}{20} & \multicolumn{4}{|c|}{25} & \multicolumn{4}{|c|}{32} \\
\hline$\downarrow$ & $\mathrm{T} \downarrow \rightarrow$ & 15 & 18 & 21 & 24 & 15 & 18 & 21 & 24 & 15 & 18 & 21 & 24 \\
\hline \multirow{5}{*}{20} & 15 & 1.00 & 0.92 & 0.61 & 0.70 & 0.48 & 0.28 & 0.33 & 0.13 & 0.51 & 0.46 & 0.41 & 0.34 \\
\hline & 18 & 0.82 & 1.00 & 0.47 & 0.60 & 0.44 & 0.37 & 0.33 & 0.12 & 0.47 & 0.38 & 0.38 & 0.29 \\
\hline & 21 & 0.72 & 0.78 & 1.00 & 0.92 & 0.75 & 0.69 & 0.68 & 0.75 & 0.64 & 0.84 & 0.70 & 0.70 \\
\hline & 24 & 0.78 & 0.57 & 0.82 & 1.00 & 0.58 & 0.55 & 0.49 & 0.63 & 0.51 & 0.64 & 0.52 & 0.60 \\
\hline & 15 & 0.59 & 0.91 & 0.94 & 0.69 & 1.00 & 0.88 & 0.85 & 0.71 & 0.94 & 0.88 & 0.96 & 0.79 \\
\hline \multirow[t]{3}{*}{25} & 18 & 0.72 & 0.98 & 0.88 & 0.59 & 0.91 & 1.00 & 0.87 & 0.86 & 0.74 & 0.87 & 0.91 & 0.84 \\
\hline & 21 & 0.59 & 0.80 & 0.95 & 0.71 & 0.93 & 0.85 & 1.00 & 0.85 & 0.66 & 0.82 & 0.92 & 0.73 \\
\hline & 24 & 0.46 & 0.60 & 0.89 & 0.75 & 0.87 & 0.82 & 0.94 & 1.00 & 0.51 & 0.79 & 0.79 & 0.81 \\
\hline
\end{tabular}




\begin{tabular}{llllllllllllll}
\hline \multirow{3}{3}{32} & 15 & 0.86 & 0.68 & 0.59 & 0.28 & 0.79 & 0.84 & 0.58 & 0.55 & 1.00 & 0.76 & 0.88 & 0.69 \\
\cline { 2 - 12 } & 18 & 0.55 & 0.81 & 0.87 & 0.70 & 0.95 & 0.78 & 0.86 & 0.79 & 0.74 & 1.00 & 0.87 & 0.85 \\
\cline { 2 - 12 } & 21 & 0.60 & 0.82 & 0.86 & 0.54 & 0.91 & 0.96 & 0.82 & 0.81 & 0.81 & 0.78 & 1.00 & 0.84 \\
\cline { 2 - 12 } & 24 & 1.00 & 0.89 & 0.86 & 0.62 & 0.93 & 0.95 & 0.86 & 0.88 & 0.83 & 0.85 & 0.94 & 1.00 \\
\hline
\end{tabular}

